\title{
VALUES VERSUS INTERESTS IN THE EXPLANATION OF SOCIAL CONFLICT
}

\author{
DENNIS CHONG†
}

Custom reconciles us to everything.
-Edmund Burke, A Philosophical Inquiry ${ }^{1}$

\section{INTRODUCTION: TWO APPROACHES TO EXPLAINING SOCIAL CONFLICT}

Social norms are standards of social control. They establish ideal forms of behavior, assign value to different points of view and ways of life, and affect individual choice by increasing the attractiveness of certain alternatives over others. Norms are manifest in all walks of life, in our personal relationships, families, churches, schools, and places of employment, at social functions, on the street, and in the marketplace. Social norms depend for their enforcement on widespread recognition within one's social group that a general consensus exists around the norm. Some social norms are backed by the force of legal authority, but not all laws have the characteristics of social norms. Many laws are foreign to people insofar as they do not resonate like a social norm and do not strike people as obviously right or wrong. ${ }^{2}$ Conflict over social norms is often upheld as a prime area where economic or rational choice models do not possess substantial explanatory power. ${ }^{3}$ Economic models, according to this view, are best suited to studying

† Professor, Northwestern University Department of Political Science and Northwestern University Center for Urban Affairs and Policy Research. I thank Patti Conley, Susan Liebell, Anna Marshall, and Meredith Woo-Cumings for reading and commenting on an earlier draft of this Article. I also thank Lisa Bernstein, Jason Johnston, Richard McAdams, and Eric Posner for organizing the Symposium on Law, Economics, and Norms at the University of Pennsylvania Law School, where this paper was originally presented.

' EDMUND BURKe, A PHILOSOPHICAL INQUIRY INTO THE ORIGIN OF OUR IDEAS OF The Sublime and BeAuTiful (J.T. Boulton ed., Columbia Univ. Press 1958) (2d ed. 1759).

2 See DONAld Black, The Behavior of LAw 105-21 (1976) (discussing the relationship between law and other forms of social control, including social norms).

s See, e.g., Joseph R. Gusfield, Symbolic Crusade: Status Polrtics aNd The AMERICAN TEMPERANCE MOVEMENT 18 (1963); Richard Hofstadter, The PseudoConservative Revolt, in THE NEw AMERICAN RIGHT 33 (Daniel Bell ed., 1955); Seymour M. Lipset, The Sources of the "Radical Right", in THE NEW AMERICAN RIGHT, supra, at 166. 
conflicts over material interests rather than differences over ways of life. People pursue not only material benefits from the government in the form of economic policies and government programs, but also status or prestige benefits through government regulation of lifestyles. Social conflict over norms supposedly revolves around concerns about status and symbolic goals instead of pocketbook calculations. The idea of "status politics," for example, has been used to explain attempts by groups to pass laws that certify their cultural values and beliefs as the dominant norms of society. In a classic formulation, the historian Richard Hofstadter wrote:

Besides their economic expectations, people have deep emotional commitments in other spheres-religion, morals, culture, race relations-which they also hope to see realized in political action. Status politics seeks not to advance perceived material interests but to express grievances and resentments about such matters, to press claims upon society to give deference to non-economic values. As a rule, status politics does more to express emotions than to formulate policies."

In general, theories of action that give priority to group ties and values have been dubbed sociological or social-psychological explanations, as opposed to economic or rational choice explanations. ${ }^{5}$ In their ideal form, sociological explanations ground the motivation for behavior in people's attachment to social norms and primary group identifications rather than in their assessment of opportunity costs. Economic explanations, on the other hand, focus on the intentions of the agent, who chooses among alternative courses of action depending on the rewards that each alternative promises. ${ }^{6}$ Rational behavior is motivated by the relative attractiveness of different alternatives rather than by the agent's deeply imprinted values, identities, and dispositions.

In the sociological view, changing behavior requires changing underlying values and dispositions, whereas in the economic view, behavior alters when rewards for different choices are changed. Values and dispositions, however, are said to be difficult to change, which is why they often prevail over considerations of self-interest. ${ }^{7}$

\footnotetext{
' Richard hofstadter, The Paranoid Style in American Politics 87 (1965).

${ }^{5}$ See BRIAN BARRY, SOCIOLOGISTS, ECONOMISTS, AND DEMOCRACY 4 (1978); JON Elster, THe CEMENT of SOCIETY: A STUdy OF SOCIAL Order 97, 99 (1989).

${ }^{6}$ See ELSTER, supra note 5, at 97.

${ }^{7}$ See Norval D. Glenn, Values, Attitudes, and Beliefs, in Constancy and Change IN Human Development 596 (Orville G. Brim, Jr. \& Jerome Kagan eds., 1980); David O. Sears, The Persistence of Early Political Predispositions: The Roles of Attitude Object and
} 
Social values are the product of one's family, school, social class, church, and other groups and institutions that shape one's socialization experiences and cause one to internalize certain values and group identifications rather than others. A person's preferences and actions are therefore determined by the values that have been inculcated in him: those with higher education are more likely to support the mainstream norms of the system because they are better integrated in society and have been more heavily exposed to the institutions that promote these norms; children learn their partisanship from their parents and are likely to vote for the same political party when they become of age; and religious individuals give stronger support to conservative candidates than those who are less devout because these candidates appeal to their traditional attitudes and values.

Alternatively, political values can be explained in terms of intentional actions and strategic calculations. Interests shape values, which, in combination with assessments of the costs and benefits of available alternatives, determine choices. From this rational choice perspective, people are motivated by instrumental reasons to adopt the opinions that they hold, whereas in the sociological view howand indeed whether-an individual thinks about politics depends largely on the way he has been socialized rather than on strategic considerations.

Despite the infiltration of economic reasoning into many areas of social science, research on attitude and opinion differences (on both economic and noneconomic issues) has successfully resisted the impulse to trace the formation of attitudes and the origins of group conflict primarily to self-interested motivations. In fact, the received view among political scientists continues to be that with few exceptions self-interested motivations do not significantly affect a person's stance on political issues. ${ }^{8}$ Research on political attitudes instead emphasizes political socialization, cultural values, personal traits and dispositions, and social learning processes as explanatory factors, which reflects the sociological and social psychological heritage of the research. ${ }^{9}$ True to such origins, the

Life Stage, in 4 Review OF Personality and Social Psycholocy 79 (Ladd Wheeler \& Phillip Shaver eds., 1983).

${ }^{8}$ See Donald R. Kinder \& David O. Sears, Public Opinion and Political Action, in 2 HANDBOOK OF SOCIAL PSYCHOLOGY 659 (Gardner Lindzey \& Elliot Aronson eds., 3d ed. 1985); David O. Sears \& Carolyn L. Funk, Self-Interest in Americans' Political Opinions, in BEYOND SELF-INTEREST 147 (Jane J. Mansbridge ed., 1990).

${ }^{9}$ See generally Paul M. SNiderman et al., Reasoning and Choice: Explora- 
individual at the center of these studies is not a rational maximizer who takes any position and follows any course that increases his personal welfare, but rather a much less flexible creature of political socialization and conformity, whose views reflect deep-seated personality characteristics, the enduring impact of cultural values and norms learned early in life, and the pervasive influence of reference groups and elite opinion leaders.

As I elaborate in Part I, the best evidence for the sociological model is that values and group identifications often seem to develop without respect to self-interest and to motivate actions that ignore opportunity costs. One aim of this Article is to discuss how rational choice can account for some of this behavior, although ultimately I believe that the sociological view has merit. The Article's main purpose, however, is to show that, by giving short shrift to the role of interests, the sociological approach fails to provide a coherent explanation of how social norms and values are formed and why they represent a continual source of conflict. I will not simply recast the story of how norms develop along lines that are consistent with a rational choice explanation; rather I will argue that an explanation of social conflict that does not treat norms and values strategically leaves unresolved the origin of group norms and group differences, the motivation behind conformity to group norms, and the reasons why people defend their norms and seek to impose their norms on others. In Parts II through VII, I enumerate several ways that interests and rational decision making support the values and norms we learn and defend as members of groups. First, general values such as those encompassed within a political ideology may serve as long-term commitments to a way of life that allow one to make sense of the world and to economize on decisions. ${ }^{10}$ Second, decision making is sometimes guided by values that constitute beliefs about which alternative best serves one's interest. ${ }^{11}$ Third, social norms sometimes follow from calculated considerations of self or group interest. ${ }^{12}$ Fourth, an explanation of social conformity processes around group norms rests on the mechanism of self and group interest. ${ }^{13}$ Fifth, even when the sub-

TIONS IN POLITICAL PSYCHOLOGY (1991); JOHN R. ZALlER, THE NATURE AND ORIGINS OF MASS OPINION (1992).

${ }^{10}$ See infra part II.

"See infra part III.

12 See infra part IV.

13 See infra part V. 
stance of the group norm does not directly serve one's interest, it can be in one's interest to conform when the norm represents a social convention that everyone has an interest in supporting so long as others do so. ${ }^{14}$ And lastly, irrespective of whether values are formed out of self-interested calculations, there are likely to be self-interested reasons to defend those values against intrusion once people have invested in them through their earlier decisions. ${ }^{15}$

While emphasizing the role that rationality and strategy play in disputes over social norms, I doubt that these conflicts can be understood completely in such terms. In Parts VIII and IX, I argue that there appears to be an irreducibly nonrational element in social conflicts stemming from the manner in which people draw inferences and generalizations about those who are different from themselves and develop cultural theories based on such faulty assumptions. These cultural theories defend group traditions and practices as being essential to political and economic progress, and popular subscription to such theories accounts for much of the animus behind defense of the status quo. But despite the prevalence of these folk theories, people still act in conventionally strategic waysprotecting their political position, coordinating action on the basis of existing coalitions, using government to legislate against supposedly pernicious ideas and threatening groups - when they put these theories into practice. ${ }^{16}$

\section{The Nature of Social Values}

\section{A. Cultural Habit and Inertia}

One would think that former Oregon Senator Bob Packwood, while dogged by charges that he had a history of making unwanted sexual advances to women and while under investigation by the Senate Ethics Committee, would have stopped telling sexual jokes in public and would have resisted the temptation to compliment pretty women. Indeed, a person accused of sexual misconduct might be expected to smarten up and become especially vigilant about his own behavior, especially around women. But apparently Packwood remained prone to such lapses, forcing his chief of staff

\footnotetext{
${ }^{14}$ See infra part VI.

${ }^{15}$ See infra part VII.

${ }^{16}$ See infra parts VIII-IX.
} 
to watch sternly over him and step in whenever she saw that he was about to cross the line. ${ }^{17}$

Habits learned, ingrained, and positively reinforced over a lifetime die hard. When Packwood was growing up, he was painfully shy. Aware that he was socially inept, he read Dale Carnegie's How to Win Friends and Influence People ${ }^{18}$ to learn ways to compensate. ${ }^{19}$ Apparently he collected bawdy jokes in a notebook and systematically committed them to memory, perhaps because he found it easier to fit in by being funny. ${ }^{20}$ For much of his adult life, the training he undertook to improve his social skills served him adequately. He never came close to being comfortable with the glad-handing that politicians are famous for, but he took steps to develop appealing personal characteristics that he knew he would need in greater measure to be successful. ${ }^{21}$ The irony in Packwood's case is that times have changed and relationships between the sexes in and out of the workplace have been redefined, but unfortunately the traits that Packwood so deliberately learned to smooth his path continue to rule him like an addiction, prompting behavior that is no longer tolerated. ${ }^{22}$ The values and dispositions that he cultivated over a lifetime have become stubbornly unresponsive to his new interests.

If there is a single lesson to draw from the sociological model, it is that individuals often make choices largely out of habit or inertia, without engaging in much, if any, strategic calculation. In practice it may be indeterminate whether habit reflects a prior commitment to a course of action involving some earlier measure of rational reflection, or if it merely reflects mindless repetition; nevertheless, it seems that with changes in the feasible set, behavior often displays more rigidity than economists acknowledge. For example, just as Packwood had difficulty shaking his old style, innercity youths, who must project fearlessness-by the clothes they wear, the language they use, and the way they move-in order to survive

${ }^{17}$ See Peter J. Boyer, The Ogre's Tale, NEw Yorker, Apr. 4, 1994, at 36, 45.

${ }^{18}$ Dale Carnegie, How to Win Friends and INFluence PeOPLe (1936).

${ }^{19}$ See Boyer, supra note 17, at 39.

${ }^{20}$ See id. at 41 .

${ }^{21}$ See id. at 39 (noting that Senator Packwood compensated for his lack of conviviality with strenuous homework, maintaining an enormous system of index cards bearing the names of almost all the people he ever met in his political career, "systematically organized by name and region").

22 See id. at 41 ("Packwood has been caught in a wind shear of the Zeitgeist-he is not a terribly sympathetic figure whose loutishness was once accepted, if not acceptable, but now confronts him like an indictment."). 
on the street, ${ }^{23}$ have trouble adjusting to the norms of "decent" behavior required at school and on the job. ${ }^{24}$ As Elijah Anderson explains, "The street-oriented youth ... has made the concept of manhood a part of his very identity; he has difficulty manipulating it-it often controls him. ${ }^{\text {25 }}$

The inertia contained in beliefs and values often prevents people from recognizing that conditions have changed. Scottish and Irish immigrants, for example, accustomed to wood shortages in the Old World, continued to build small houses in this country even though wood was abundant in their new surroundings. ${ }^{26}$ As Jon Elster observed, "people sometimes act stupidly out of stupidity and rigidly out of rigidity. Inertia may be a rational way of coping with a too rapidly changing environment, but it may also be just what it is: inertia." ${ }^{27}$ Beliefs and values are rooted in emotions and sensibilities that are not easily controlled or altered voluntarily. They have a hold on the mind that may not be loosened by new circumstances and changes in incentives. Cultural practices, therefore, tend to persist even after the environmental constraints that gave rise to them no longer exist.

\section{B. Status Politics}

The stubborn persistence of group identifications at the expense of material interests underlies theories of status politics. ${ }^{28}$ Status $80,88$.

${ }^{23}$ See Elijah Anderson, The Code of the Streets, ATLANTIC MONTHLY, May, 1994, at

${ }^{24}$ See id. at 92.

$25 \mathrm{Id}$.

${ }^{26}$ See Forrest McDonald, Prologue to Grady McWhiney, Cracker Culture: Celtic Ways IN THE OLd SOUTH at xxii (1988).

${ }^{27}$ JON ELSTER, ULySSES AND THE SIRENS: STUdies IN RATIONALITY AND IRRATIONALITY 139 (1984).

${ }^{28}$ See, e.g., MURRay Edelman, The Symbolic Uses of politics 29 (1964); GUSFIELD, supra note 3, at 139-65 (noting that certain values may be promoted for status rather than material interests); HOFSTADTER, supra note 4, at 23 (asserting that a "nonrational reaction to symbols among people sharing a common governmental interest" is a crucial aspect of the political process); SEYMOUR M. LIPSET \& EARL RAAB, THE POLITICS OF UNREASON: RIGHT-WING EXTREMISM IN AMERICA, 1790-1970 (1970) (explaining the sources of right-wing extremism in American history and politics); Louis A. Zurcher \& R. GeORGe KIRKPATRICK, Citizens fOR DECENCY: ANTIPORNOGRAPHY CRUSADES As STATUS DEFENSE (1976) (using the theory of status politics to explain community conflict over the distribution of sexual material). This assumption is also the guiding premise of the symbolic politics literature. See, e.g., Kinder \& Sears, supra note 8. For a further discussion of the central claims in the symbolic politics literature, see infra part I.C. 
politics is essentially group politics organized along the social dimension. The sociologist Joseph Gusfield developed a variation of this theory in his account of the Temperance movement at the turn of the century. Gusfield contended that Prohibition and Temperance represented struggles between new and traditional groups over the legitimacy and status of their respective habits and lifestyles.

Both sides in the conflict tried to use public policy as a way to assert their preeminence in the social order: ${ }^{29}$

Status issues indicate, by their resolution, the group, culture, or style of life to which government and society are publicly committed. They answer the question: On behalf of which ethnic, religious, or other cultural group is this government and this society being carried out? We label these as status issues precisely because what is at issue is the relevant groups in the status order of the society. ${ }^{30}$

Gusfield argued that people do not pursue status issues to enhance their economic position.

[Rather a] political issue becomes one of status when its tangible, instrumental consequences are subordinated to its significance for the conferral of prestige. ... The argument is less over the effect of the proposed measures on concrete actions than it is over the question of whose culture is to be granted legitimacy by the public action of government. ${ }^{31}$

The historian Richard Hofstadter advanced a similar theory to explain conservative and reactionary politics in the $1950 \mathrm{~s}^{32} \mathrm{He}$ acknowledged that political and economic grievances concerning taxes, inflation, and the quality of life in the cities accounted for part of the motivation behind the conservative agenda in the postWorld War II period, but he was not persuaded that the essential features of the movement could be accounted for in material terms. $^{33}$ In addition to such economic concerns, there were cultural and symbolic elements driving political action that did not easily lend themselves to economic interpretation-"among them the

${ }^{29}$ GuSFIELD, supra note 3 , at 166 ("The agitation and struggle of the Temperance adherents has been directed toward the establishment of their norms as marks of social and political superiority.").

${ }^{30}$ Id. at 173.

${ }^{31} I d$. at 148.

s2 See HOFSTADTER, supra note 4, at 41-65.

ss See id. at 49. 
sheer weight of habit and party loyalty, ethnic origins and traditions, religious affiliations and religious styles, racial and ethnic prejudices, attitudes toward liberty and censorship, feelings about foreign policy quite unrelated to commercial goals and of dubious relationship to the national interest." ${ }^{34}$

In particular there were several anomalies concerning the conservative political movement of the 1950 s, such as why its proponents reacted to international insecurity and instability by demanding rigid domestic conformity, or why so much suspicion was directed at the government, almost irrespective of the partisanship of the incumbent administration.

$[N]$ one of these things seem to explain the broad appeal of pseudo-conservatism, its emotional intensity, its dense and massive irrationality, or some of the peculiar ideas it generates. Nor will they explain ... why the rank-and-file janizaries of pseudoconservatism are so eager to hurl accusations, write letters to congressmen and editors, and expend so much emotional energy and crusading idealism upon causes that plainly bring them no material reward. ${ }^{35}$

Hofstadter postulated that episodes of status politics alternated with conventional interest politics, depending on the condition of the economy. In a troubled economy, groups direct their energies toward programmatic and legislative solutions for their material grievances. ${ }^{36}$ In times of economic prosperity and social mobility, however, certain social groups become vulnerable to changes in the social order and resort to desperate measures to retain their social position. $^{37}$ Hofstadter suggests that certain poorly understood psychological dynamics are at work:

For the basic aspirations that underlie status discontent are only partially conscious; and, even so far as they are conscious, it is difficult to give them a programmatic expression.... Therefore, it is the tendency of status politics to be expressed more in vindictiveness, in sour memories, in the search for scapegoats, than in realistic proposals for positive action. ${ }^{38}$

st Id. at 91-92.

${ }^{35} I d$. at 49.

${ }^{36}$ See id. at 53 ("During depressions, the dominant motif . . . takes expression in proposals for reform or in panaceas. Dissent then tends to be highly programmaticthat is, it gets itself embodied in many kinds of concrete legislative proposals.").

${ }^{37}$ See id. at 53-54 ("In prosperity. . . there is a tendency to embody discontent not so much in legislative proposals as in grousing.").

${ }^{38}$ Id. at 53-54. 
The crux of the issue concerning status politics is in what sense it merits a special category: Why do people care about symbolic matters if they are not otherwise instrumental or translatable to other benefits? If the issues defining status politics are more expressive than instrumental in character, then why do the symbols and norms related to these issues reliably transmit across generations, and why does it matter whether individuals conform to them? Are there no material consequences to having one set of cultural norms and symbols predominate over another? Why do groups develop strong attachments to their norms and practices? I argue that a pure conception of status politics cannot withstand scrutiny along these lines, and that attachments to a certain way of life serve broader, more instrumental purposes than the proponents of status politics generally acknowledge. ${ }^{39}$

Rational individuals try to improve their life circumstances by increasing not only their material resources, but also their status and power. ${ }^{40}$ They attempt to do so through individual and group efforts because they are treated by others in terms of both their individual qualities and their group affiliations. Social norms are contested because they coordinate action and codify the respectability of different kinds of behavior and different kinds of groups. The capacity of norms to attach legitimacy to certain forms of behavior can have an important differential material impact on people. A neat boundary, therefore, cannot be drawn between the symbolism of a norm and its corollary instrumental ramifications. The stigmas created or lifted by social norms affect life opportunities. For example, when groups are denied equal status by law, they suffer more prejudice and thus are more likely to experience discrimination in employment and housing and to be treated unequally in social relations. The stigmatized group's interests are harmed by the damaging effects of the law on people's attitudes and values; popular attitudes in turn have social and economic implications because they affect choices and preferences. Stigmas can also inhibit political mobilization and participation in the democratic process. Members of illegitimate groups who might press for policies that support their interests may be reluctant to reveal themselves publicly in order to do so. ${ }^{41}$ Status, in short, is a vital

${ }^{39}$ See infra parts IV-VII.

${ }^{40}$ Class, status, and power are of course the three classic dimensions of social stratification. See generally CLASS, STATUS AND POWER (Reinhard Bendix \& Seymour M. Lipset eds., 2d ed. 1966).

${ }^{41}$ Recent state campaigns to repeal state and local laws barring discrimination 
economic and political resource, and it is important to view status as a system of rewards interrelated with social and material benefits.

\section{Symbolic Politics}

Some of the strongest empirical evidence for the resilience of group identifications and values appears in a collection of recent studies which argue that there is at best a tenuous connection between people's life circumstances (or self-interests) and their public policy stance. ${ }^{42}$ These studies suggest that so-called symbolic orientations such as political ideology, party identification, racial tolerance, and other general values bear most of the responsibility for shaping policy preferences. These studies have tried to assess the relative influence of values and self-interest on policy preferences by looking at how changes in opportunity costs affect choices. Because these studies are cross-sectional, however, we only see how cross-sectional variation in opportunity costs affects marginal distributions of opinion. For example, does having a school-age child affect whether one supports school busing beyond the influence of one's ideological and racial beliefs? The verdict is that, even when the costs of a policy preference are altered by changes in life circumstances, the influence of the deep-seated value persists. ${ }^{43}$ The same is true on issues of law and order, government employment policy, and health insurance. For example, a crime victim who behaves according to the economic model presumably updates his information about the relative safety of his community after having been victimized; however, survey data show that whether or not one has been victimized actually has little effect on policy preferences. ${ }^{44}$ Similarly, whether one has health insurance or is employed seems to make only a marginal difference in whether one supports government programs to provide health

against homosexuals have posed a dilemma for gay citizens who wish to contest such measures, but who are afraid to do so because they wish to keep secret their homosexuality. Despite their reluctance, many homosexuals feel compelled to take a public stance in order to prevent such initiatives from further stigmatizing them. They also hope that by 'coming out' and demonstrating to society that they are normal, popular attitudes toward them will change. See Dirk Johnson, Idaho's Homosexuals 'Coming Out' to Cast Debate in Neighborly Terms, N.Y. TIMES, June 30, 1993, at Al0.

12 For a survey, see Sears \& Funk, supra note 8.

is See David O. Sears et al., Self-Interest vs. Symbolic Politics in Policy Attitudes and Presidential Voting, 74 AM. POL. SCI. REV. 670, 675 (1980).

${ }^{14}$ See id. 
coverage and jobs. ${ }^{45}$ In general, changes in opportunity costs influence choices weakly, if at all. Why does self-interest appear to have so little effect on opinion?

One possibility is that self-interest is typically overwhelmed by long-held, emotionally powerful predispositions. According to this account, people acquire predispositions (like racial prejudice or nationalism) early in life that shape their political views in adulthood. Interpretation and evaluation of political events are essentially affective responses to salient symbols that resemble the attitude objects to which similar emotional responses were conditioned in earlier life. Whether or not the event has some tangible consequence for the citizen's personal life is irrelevant; the pertinent personal stake is a symbolic one, which triggers longheld, affect-laden, habitual responses. ${ }^{46}$

There are two problems with this reasoning. It provides at best an abbreviated explanation for the source of values, and it insists that certain immutable elemental beliefs and values learned early in life are retained indefinitely for non-self-interested motives. Therefore, the symbolic model provides no convincing account of why some attitudes and values are endorsed and promoted rather than others, nor of how cultural values and norms occasionally change. But any time we claim to be explaining social values, we are really trying to explain the reasons underlying changes in social values over time. It is difficult to account for such change without examining the incentives that people have to adopt or reject new values and to promote or prevent value change in others.

If interests truly are irrelevant, where do values come from? Sears and Funk reject the possibility that self-interest, as reflected in class or economic status, shapes partisan and ideological preferences because symbolic predispositions tend to be formed early in life and are not easily altered by short-term material concerns. ${ }^{47}$ The difficulty with this argument is that, even if one accepts its premises, the conclusion does not follow. A child who is socialized to believe in values without fully comprehending their ramifications conforms at least partly in response to inducements

${ }^{45}$ See id. at $670-84$.

${ }^{46}$ Kinder \& Sears, supra note 8, at 671-72; see also TAlcotT PARSONS, THE SOcIAL SYSTEM 208 (1951) ("[A]mong the learned elements of personality in certain respects the stablest and most enduring are the major value-orientation patterns and there is much evidence that these are 'laid down' in childhood and are not on a large scale subject to drastic alteration during adult life.").

${ }^{47}$ See Sears \& Funk, supra note 8, at 162. 
and punishments controlled by his parents, school teachers, and other role models. By the same token, those given the responsibility for socializing children, especially parents, choose to transmit certain values rather than others at least partly because they think these values will be useful for their children to live by. ${ }^{48}$

Admittedly, it is an exaggeration to say that interests account entirely for the values that people convey to others in the socialization process. People rarely communicate values in a strategic manner (as is the case with propaganda); they often simply express them as opinion. Brian Barry notes that " $[$ s]ometimes ... the explanation [for cultural stability] may be something humdrum like the tendency of parents to bring up children with the same outlook as themselves, or, in some fundamental ways, to reproduce their own childhood." 49 As he points out, parents do not always teach their children to look after their elders in their old age, even though it would be in their interest to do so. ${ }^{50}$ I would add that parents unavoidably convey values in their words and actions, whether they mean to or not, and children naturally pick up on their biases. Some values are displayed because parents think it is important that their children hold certain beliefs in order to become better people; but ideas can also be transmitted unintentionally, as parents who watch what they say around their children realize. Parents also recognize that certain values they hold (such as risk aversion or envy, perhaps) are detrimental to their well being and prefer that their children not reproduce them. Yet parents may have great difficulty changing their views for their own good and the good of their children, even though they recognize the harm involved.

\section{VAlues As LONG-TeRM COMMITMENTS}

Relegating self-interest to short-term material and personal concerns-as the symbolic politics literature does-virtually ensures that self-interest will take a back seat to general values and dispositions in terms of their relative explanatory power. A similar bias undercut early research on the prevalence of policy voting, when partisan voting was kept separate conceptually from issue voting. ${ }^{51}$ part V.

${ }^{48}$ For a further discussion of the interests behind social conformity, see infra

${ }^{49}$ BARRY, supra note 5 , at $97-98$.

${ }^{50}$ See id. at 98.

51 The classic study, defining the Michigan model of voting behavior, is ANGUS CaMpbell et al., The AMERICAN VOTER (1960). 
Critics rightly argued that party-line voting was not inconsistent with an economic approach.

Most voters will only learn enough to form a very generalized notion of the position of a particular candidate or party on some issues, and many voters will be ignorant about most issues. The investor-voter will use partisan and ideological labels as practical solutions to the problem of costly information. ${ }^{52}$

In the research on symbolic politics, the same criticism can be levied. A person's racial tolerance or political ideology may be a better predictor of his views on school busing than whether he has school-age children, but there is no reason to assume that following such values occurs independently of interests.

The pursuit of values may accord with rational action if one considers what values embody and what it means to follow them. Values explain by offering reasons for individual action that go beyond merely summarizing the behavior itself. While the best evidence for motivation by a particular value may be a pattern of consistent behavior, a reference to values focuses on a particular reason for the person's actions, as opposed to alternative reasons. It is not incumbent that values be the first cause or ultimate factor driving the explanation in order for values to constitute a valid explanation. They merely have to represent one of the links in a causal chain. ${ }^{33}$

Ideologies represent the broadest kinds of values that people employ in their decision making. In their most advanced form, ideologies comprise organized systems of belief pertaining to the nature of man, the rights of citizens, the ideal way to organize society, the proper role of the state, the wisdom of programmatic change, and the prerequisites of a good society. Although most people do not have such developed ideological beliefs, they do acquire attitudes and feelings toward different ideological camps. ${ }^{54}$ The prevailing social psychological view is that general ideological leanings are acquired very early in life mainly from parents, while

52 Samuel Popkin et al., What Have You Done for Me Lately? Toward an Investment Theory of Voting, 70 AM. POL. SCI. REV. 779, 787 (1976); see also MORRIS P. FIORINA, RETROSPECTIVE VOTING IN AMERICAN NATIONAL ELECTIONS 65-83 (1981) (presenting a model of party identification that incorporates voter assessments of past party performance).

${ }^{33}$ See BARRY, supra note 5, at 89-96.

st See Herbert McClosky \& John Zaller, The american Ethos: Public AtTrtudes Toward Captralism AND Democracy 189-233 (1984). 
particular views on political subjects remain hazy in the years prior to adulthood. ${ }^{35}$

Ideological leanings therefore entail preferences for bundles of goods. People have first-order desires as well as reflective secondorder desires about those desires (or metapreferences). ${ }^{56}$ Switching from being a meat-eater to being a health conscious vegetarian represents a change in lifestyles, not simply a change of a single preference ordering. Each lifestyle is accompanied by an overall set of preferences that one conforms to if the lifestyle is followed. But if one abandons the lifestyle for another, then a substitute set of preferences must be followed. An ideology similarly consists of principles or rules that shape preferences across a range of alternatives and on numerous dimensions. As a constellation of values, a political ideology commits one to a variety of preferences that guide one's actions over the long haul. Switching ideologies entails switching the rules that one uses to make choices. The rules might be abstract or they may be as simple as adopting whatever position is endorsed by the experts. Isolated short-term factors (for example, losing one's job, being robbed, etc.) that could potentially change one's values are likely to be resisted because they run against the ideological rules to which one has developed a commitment.

The connection. between ideological values or ideological policies and the material interests of individuals is seldom straightforward. For pragmatic reasons, liberal and conservative ideologies in American politics are intended to hold together broad electoral coalitions and thus offer prescriptions about how to improve conditions for a diverse cross-section of society. Therefore, there need not be sharp class differences in support for liberalism and conservatism because both philosophies claim to be best for society as a whole, as well as the constituent groups in society. The socioeconomic biases of ideological and partisan identification are consistent with a self-interest model, but the correlations are far from perfect and leave room for many other social and psychological factors that affect one's ideological development. ${ }^{57}$

35 See Duane F. Alwin et al., Poldtical attitudes over the Life Span 21 (1991) (noting that young children acquire "primitive partisan attitudes to a number of political and social objects in the early and middle grade-school years").

${ }_{36}$ See Albert O. Hirschman, ShifTING Involvements 70-71 (1982); Harry G. Frankfurt, Freedom of the Will and the Concept of a Person, 68 J. PHiL. 5, 6-7 (1971) ("Besides wanting and choosing and being moved to do this or that, men may also want to have (or not to have) certain desires and motives.").

${ }^{37}$ See LIPSET \& RAAB, supra note 28, at 452-82; see also HeRBERT MCClosky \& 
The main interest served by an ideology therefore may not be a direct material interest, but an interest in establishing a coherent understanding of society and of providing a relatively consistent representation of oneself to others. Such values still have to enjoy some sources of support and reinforcement if they are to retain significance. This support is partly psychological; early learning leaves a deep imprint that cannot easily be erased by contemporary events. But there are also important social and political supports for ideological and group identifications. Once such identifications exist, it is rational for community leaders and politicians to try to make them salient and to appeal to them, and it can be rational for citizens to act in concert with others who hold the same identification.

In addition to simplifying decision making and providing a foundation for group organization, attitudes and values represent an important element of a person's self-presentation. ${ }^{38}$ Opinions are closely bound up with individuality, identity, and character; belief formation is an integral part of developing and fostering a reputation. People use values to cultivate social roles and to influence other people's expectations about themselves that, in their view, will prove useful, advantageous, or adaptive in future social interaction. However, there are social constraints on people's ability to define and redefine themselves. People tend to assume that others are guided by a consistent core of attitudes and dispositions that account for their behavior. Excessive changes in one's beliefs and attitudes raise uncertainty about one's personality and character in addition to questions about one's reliability and stability.

\section{VAlues Shape Beliefs About Alternatives}

Ideological values also affect beliefs about social causality. People have a rough understanding about what kind of government serves their individual and group interests. For instance, they might feel strongly one way or another about government intervention in the economy. Even if people act primarily in response to the

Alida Brill, Dimensions of TOlerance 336-414 (1983); Dennis Chong et al., Patterns of Support for Democratic and Capitalist Values in the United States, 13 BRrT. J. POL. SCI. 401 (1983); Herbert McClosky \& Dennis Chong, Similarities and Differences Between Left-Wing and Right.Wing Radicals, 15 BRrT. J. POL. SCI. 329 (1985).

${ }^{58}$ See Albert O. Hirschman, Having Opinions-One of the Elements of Well-Being?, AM. ECON. REV., May 1989, at 75. 
advantages and disadvantages of the options presented to them, they still economize in their decisions by developing and relying on rules and information embodied in their attitudes, beliefs, and values.

The influence of opportunity costs on policy positions would probably be much greater if people had better information. There is a significant relationship, for example, between home ownership and support for property tax cutbacks because people can more readily see the economic ramifications of this issue. ${ }^{39}$ On many issues, however, it is difficult for people to know what policy is best for them. For example, groups that are disadvantaged or that have been the victims of discrimination must weigh the advantages and disadvantages of different routes to improvement. There is so much uncertainty surrounding the various alternatives, however, that the best choice is perhaps as much a product of persuasion as objective evidence. Earlier this century blacks must have experienced such difficulty weighing the competing ideas of Booker $\mathrm{T}$. Washington and W.E.B. DuBois. These two leaders promoted different routes to social advancement and had different ends in mind-vocational versus college training, tolerance of segregated institutions versus pursuit of complete social and political equality. The emphasis placed by DuBois and the NAACP on social equality and civil rights resonated more strongly among middle class blacks, while Washington's ideas appealed to rural and working class blacks.

Ideological values concerning the motivations of individuals, the efficacy of the state, and the wisdom of social programming and radical change will influence beliefs about the effects of available alternatives. Such values therefore shape both preferences and beliefs about the feasible set. That such values guide choice accords with an economic model of decision making in which people optimize among the available alternatives given their knowledge and beliefs. Mass survey studies of the relationship between self-interest and policy choices, however, invariably ignore how beliefs about the alternatives affect individual choice. For example, studies assume that those without health insurance or employment should support government intervention in these areas. ${ }^{60}$ But what these studies overlook is some assessment of how those without health insurance

${ }^{39}$ See David O. SEARS \& Jack Citrin, TAX REVOLt: SOMETHING FOR NOTHING IN CALIFORNIA 45-46 (1982) (analyzing public opinion and voting behavior on Proposition 13 in California).

${ }^{60}$ See Sears et al., supra note 43, at 680. 
or the unemployed regard the prospect of government health insurance as opposed to private insurance or government policies to combat unemployment. Someone might lose his health insurance coverage, but still not want government intervention because he believes the state cannot efficiently manage such programs.

These criticisms notwithstanding, research on symbolic values performs an important service by refuting simplistic economic theories that assume that objective changes in personal resources and circumstances will automatically affect choices. In other words, the person who loses his job will not suddenly want the government to provide everyone with a guaranteed job; the parents who produce a new child will not reverse their stand on busing and now oppose it because they are at risk; the liberal who gets mugged one evening will not wake up as a conservative opposed to gun control and in favor of mandatory prison terms and the death penalty. Economists unfamiliar with this empirical research may be prone to think that individual behavior is overly adaptive.

\section{VALUES DERIVED FROM INTERESTS}

Some values and dispositions are developed rather consciously to fit one's predicament, or to support self or group interests. These are the easy cases connecting norms and values to interests.

\section{A. The Code of the Streets}

Inner-city youths often follow a street code, which evolved from the environment in which they operate. ${ }^{61}$ It is based on the realistic assumption that they cannot rely upon the police and the courts to maintain order and settle neighborhood disputes. Consequently, inner-city residents feel the need to develop their own defense mechanisms. ${ }^{62}$ If the police will not respond to calls for assistance or if they cannot be trusted to treat residents fairly, then it becomes incumbent on them to be self-reliant, to have the

${ }^{61}$ See Anderson, supra note 23, at 82 ("[The] code of the streets . . . amounts to a set of informal rules governing interpersonal public behavior, including violence. ... The rules have been established and are enforced mainly by the streetoriented ....").

${ }^{62}$ See id. (noting that " $[t]$ he code of the streets is actually a cultural adaptation to a profound lack of faith in the police and the judicial system" who "may not respond [when called], which is one reason many residents feel they must be prepared to take extraordinary measures to defend themselves and their loved ones against those who are inclined to aggression"). 
wherewithal to defend themselves against aggression, and to adopt a demeanor that deters others from trying to take advantage of them. ${ }^{63}$

Inner-city youths have an inordinate concern (by conventional standards) with commanding respect in everyday interactions on the street. It is dangerous for someone to allow himself to be disrespected by another person because that will encourage others to test and challenge him in the future. ${ }^{64}$ In this environment, it is arguably advantageous for someone to become a ruthless person, prepared to retaliate massively-even at the risk of one's own life-in response to any disrespect shown toward him ${ }^{65}$ because those who are feared are not "messed with." They would rather die than allow disrespect to go unpunished. ${ }^{66}$ In a community that places such a high priority on respect, however, individuals constantly run the risk of violent confrontation. Widespread conformity to an individually rational adaptation therefore translates into the community equivalent of nuclear brinkmanship to the detriment of everyone. ${ }^{67}$

Residents of the inner-city often aspire to live up to so-called decent or mainstream values in their behavior. ${ }^{68}$ However, a decent disposition on the streets potentially creates ambiguity regarding one's resolve and the meaning of one's actions. A person who acts decently by walking away from a confrontation might be seen by others as either a decent person or as a person who lacks nerve and thus can be victimized with impunity. ${ }^{69}$ Under these circumstances, it is less problematic to fight when challenged

6s See id. at 88 ("[O]ne's bearing must send the unmistakable if sometimes subtle message to 'the next person' in public that one is capable of violence and mayhem when the situation requires it, that one can take care of oneself.").

${ }^{64}$ See id. ("[I]f a person is assaulted, it is important . . . for him to avenge himself. Otherwise he risks being 'tried' (challenged) or 'moved on' by any number of others.").

${ }^{65}$ See id. at 92 ("When others believe that [one is not afraid to die], it gives one a real sense of power on the streets. Such credibility is what many inner-city youths strive to achieve ... because of its practical defensive value . . ..").

${ }^{66}$ See id. ("The youths who have internalized this attitude and convincingly display it in their public bearing are among the most threatening people of all, for it is commonly assumed that they fear no man.").

${ }^{67}$ For a general discussion of "dissing" among inner-city youths, see Adeno Addis, Role Models and the Politics of Recognition, 144 U. PA. L. REV. 1377, 1425-26 (1996).

${ }^{68}$ See Anderson, supra note 23, at $82-83$ (noting that inner-city, working poor families accept mainstream values more fully than their street-oriented neighbors and attempt to instill those values in their children).

${ }^{69}$ See id. at 89. 
because there is less room for misinterpretation of the meaning of one's actions. ${ }^{70}$

\section{B. Norms Regulating the Teaching of the Law}

Professional norms commonly serve the interests of members of the profession. Other motives (for example, pedagogical theory or moral beliefs) behind the creation of the norm usually exist, but self or group interest guides and reinforces the particular form that it ultimately takes. The development of the case method of teaching law-spearheaded by Christopher Langdell, Dean of Harvard Law School-presented legal training in analytical theoretical terms. According to this approach, legal training should be rigorously scientific in the sense that one had to work inductively from the history of cases to discern the evolution of legal principles and doctrines governing a sphere of law. ${ }^{71}$ The case method gradually won out over the older lecture and textbook methods of teaching because it gave the legal profession a distinctive academic foundation that restricted and regulated membership.

It exalted the prestige of law and legal learning; at the same time it affirmed that legal science stood apart, as an independent entity, distinct from politics, legislation, and the man on the street. In this period, interest and occupational groups fought for a place in the sun. Langdell provided a firm basis of theory for certain important claims of the legal profession. Law, he insisted, was a branch of learning that genuinely demanded rigorous formal training. There was justification, then, for the lawyers' monopoly of practice. The bar association movement began at exactly that point in time which coincided with Langdell's rise to power. The two movements went hand in glove. ${ }^{72}$

The development of a standard curriculum also provided a basis for regulating the increasing proliferation of law schools. Vocationally oriented law schools catered to those from disadvantaged backgrounds. ${ }^{73}$ These schools widened access to the legal profession, thus raising concern among elite lawyers over the maintenance of their occupational status and exclusivity, as well as their income. Bar examinations helped stem the flow into the profession. University law schools raised another barrier by forming the

\footnotetext{
${ }^{70}$ See id. at 94.

$"$ See LAWrence M. FRIEdMan, A History of AMERICAN LAW 531-32, 535 (1973).

72 Id. at 536.

${ }^{73}$ See id. at 537-38.
} 
Association of American Law Schools which, along with the American Bar Association, provided accreditation to law schools. ${ }^{74}$ This development had the natural effect of creating a hierarchy among schools offering legal training, thereby making unaccredited schools less attractive to prospective law students.

\section{Doctors' Attitudes Toward Abortion}

Attitudes toward abortion have served a number of instrumental purposes for the medical profession, which explains some of the fluctuations in doctors' views on the issue over the last century and a half. In the early- to mid-nineteenth century, a mixture of ideological, scientific, moral, and economic reasons motivated "regular" or scientifically educated doctors to support laws against abortion. Doctors' belief in the Hippocratic oath, their image of themselves as protectors and savers of human life, their skepticism over the prevailing quickening theory of the inception of life, their personal feeling that women should fulfill traditional social roles-all of these factors contributed to their opposition to the practice of abortion. ${ }^{75}$

Significant practical considerations also shaped physicians' beliefs. Opposition to abortion on moral and ideological grounds forced patients seeking abortions to obtain service from "irregular" doctors who were not trained in modern medical practices. ${ }^{76}$ These doctors threatened to take patients away from regular doctors because a woman who was denied an abortion from her normal doctor might go elsewhere and never return. To protect their livelihoods, some regulars defected from the ranks and performed abortions. ${ }^{77}$ Most regular doctors, however, chose not to compromise their values and instead sought to root out their competition. ${ }^{78}$

To add insult to injury, irregular doctors also harmed the professional standing and social status of the medical profession, which prior to the nineteenth century enjoyed considerable social distinction and elite status. Regular doctors in this period tried to elevate the standing of the profession in the public eye and consolidate their political influence by licensing and regulating the

\footnotetext{
${ }^{74}$ See id. at 538.

75 See JAMES C. MOHR, ABORTION IN AMERICA 160-68 (1978).

${ }^{76}$ See id. at 37.

" 7 See id.

${ }^{78}$ See id.
} 
profession, organizing themselves into professional associations, and starting medical journals to communicate the latest research findings throughout the profession. ${ }^{79}$

By seeking legislation regulating abortions, regular doctors could retain their patients, maintain their professional solidarity and political power as an organized interest, and live up to their professional and personal beliefs. "Anti-abortion laws would weaken the appeal of the competition and take the pressure off the marginal members of the regulars' own sect. ${ }^{\text {no }}$ The anti-abortion campaign therefore conveniently served both the physicians' status and economic goals by differentiating the regulars from those who did not adhere to the scientific approach to medicine, while simultaneously undermining one of the competitive advantages that the irregulars enjoyed. "[B]y raising the abortion question and by highlighting the abuses and dangers associated with it, regular physicians could encourage the state to deploy its sanctions against their competitors. ${ }^{\text {81 }}$

The campaign also provided regular doctors with a basis for group solidarity. To distinguish themselves and shore up the social standing of their vocation, regular physicians required internal norms that would separate members from nonmembers. Regular doctors felt that they could become powerfully organized only if they had the means to regulate the behavior of members of the profession. In this period, however, doctors had no sanctions at their disposal to regulate their colleagues because there were no barriers to entry. ${ }^{82}$ Doctors therefore believed that passage of antiabortion legislation would create a legal norm that would lend official support to their professional norms and thus promote conformity with the practices of the scientific medical profession.

There is a clear parallel between the actions and rationale of the medical profession and those of the Temperance movement. Nativist groups sought Temperance legislation because they wanted the law to endorse their social practices. Prohibition undercut insurgent social groups and created a basis for nativist group identity. ${ }^{83}$ Mohr's characterization of the doctors' campaign

${ }^{79}$ See id. at 33-34.

${ }^{80} \mathrm{Id}$. at 37.

${ }^{81} \mathrm{Id}$. at 160.

82 See id. at 161-62.

${ }^{83}$ See GUSFIELD, supra note 3, at 122 ("[Prohibition legislation] demonstrated the power of the old middle classes by showing that they could mobilize sufficient political strength to bring it about and it gave dominance to the character and style 
against abortion uncovers similar motivations. "[T]he anti-abortion crusade became at least in part a manifestation of the fact that many physicians wanted to promote, indeed to force where necessary, a sense of professionalism, as they defined it, upon their own colleagues." ${ }^{\text {s4 }}$

The qualification, "as they defined it," indicates that these criteria for membership in the profession were somewhat arbitrary. ${ }^{85}$ All groups need to agree on norms that permit internal regulation of their members. Such values and norms sometimes serve coordination purposes first and are related to group interests only secondarily-or only so far as the interest is in establishing a basis for coordination and group mobilization. In the case of regular doctors, it was apparent that opposition to abortion better served their membership because opposition coincided with their personal beliefs and was contrary to the practices of irregular doctors.

\section{Mechanisms BeHINd Social CoNFORMITY PROCEsSEs ${ }^{86}$}

Although some group norms appear calculated to further the interests of group members, many group norms seem to be adopted without reflection and appear instead to be driven mainly by imitation and group identification. ${ }^{87}$ But even these seemingly mechanical processes of social conformity appear more coherent when one incorporates the influence of individual and group interests.

That political socialization seems to occur without much conscious calculation by any of the parties concerned raises problems for the rational choice model if one regards the pursuit of self-interest in explicitly calculating terms. Many acts of conformity are undoubtedly performed with complete ignorance of the consequences and potential benefits of alternatives. As Harsanyi noted, "People regard their existing customs as superior to alternative patterns of behavior because they have little reliable information about what it really would be like to live with any of

of old middle-class life in contrast to that of the urban lower and middle classes.").

${ }_{84}^{81}$ MOHR, supra note 75, at 162.

${ }^{85}$ For further discussion, see infra part VI.

${ }^{86}$ This Part draws on material from Dennis Chong, Rational Choice Theory's Mysterious Rivals, 9 CRITICAL REV. 37, 50-51, 53-56 (1995).

${ }^{87}$ NEAL E. MILIER \& JOHN DOLLARD, SOCIAL LEARNING AND IMTTATION 183-202 (1941). 
these alternatives. ${ }^{n 8}$ Although much cultural transmission has this inertial quality, it does not always violate the process of rational decision making. No individual has the resources to evaluate thoroughly all of the choices he must make, so by conforming to the status quo he takes advantage of the cumulative wisdom of the community. In effect, he operates on the assumption that existing practices have already survived a trial-and-error test. ${ }^{89}$

Tocqueville wrote in Democracy in America:

If man were forced to demonstrate for himself all the truths of which he makes daily use, his task would never end. He would exhaust his strength in preparatory demonstrations without ever advancing beyond them. As, from the shortness of his life, he has not the time, nor, from the limits of his intelligence, the capacity, to act in this way, he is reduced to take on trust a host of facts and opinions which he has not had either the time or the power to verify for himself, but which men of greater ability have found out, or which the crowd adopts. ${ }^{90}$

By this construction, then, conformity is simply an economical means by which individuals make choices and decisions with limited information. ${ }^{91}$

\section{A. Group Membership and Group Norms}

People seek membership in social groups because groups have the potential to provide them with benefits that they could not achieve on their own. Individuals contribute to the maintenance and fortification of the groups they join in return for status within the group and a share of the benefits that the group produces. ${ }^{92}$

${ }^{88} \mathrm{John}$ C. Harsanyi, Rational-Choice Models of Political Behavior vs. Functionalist and Conformist Theories, 21 WORLD POL. 513, 528 (1969).

${ }^{89}$ See Miller \& DOLLARD, supra note 87, at 10.

902 AleXIS DE TOCQUeVille, Democracy iN AMERICA 9 (Phillips Bradley ed., Vintage Books 1945) (1840).

${ }^{91}$ Still, one has to wonder why people develop such strong emotional attachments to the patterns of behavior they develop through socialization. It may be, as Donald Campbell speculated, that blind conformity is adaptive early in life because it improves the rate of transmission from parents to their offspring. See Donald $T$. Campbell, On the Conflicts Between Biological and Social Evolution and Between Psychology and Moral Tradition, 30 AM. PSYCHOLOCIST 1103, 1107 (1975) (noting that social evolution, like natural selection, describes a process by which "stupid, blind, unforesightful processes can produce adaptive wisdom" without any of the innovators, transmitters, or participants properly understanding the traditions being transmitted, and that "a universal tendency for conformity to the opinions of others may be essential to an adaptive social custom cumulation").

${ }^{92}$ See John C. Harsanyi, A Bargaining Model for Social Status in Informal Groups and 
Within every group there is an active trade in social status because high status improves one's chances of acquiring other desired goods. ${ }^{93}$ Because social status is rooted in particular social groups, it can be granted to people who conform to group values yet act in ways that are detrimental to the greater social welfare (as would be the case within criminal organizations, for instance). ${ }^{94}$

Society is comprised of a constellation of local units or collectivities, with "people's social status in the society at large . . . being determined by their status positions in various smaller groups, that is in the organization for which they work, in their occupational or professional group, in their residential community, in various social organizations, and so on. ${ }^{\text {n55 }}$ Not only do people depend on the resources provided by groups to achieve their individual interests, but the very conception of what is in their interest is affected by the information that is transmitted through groups. People also develop identities and acquire standing according to the groups with which they associate. Likewise, their social interaction is guided by the preconceptions and stereotypes that they hold about others based on their group ties. ${ }^{96}$

Each social stratum is defined by norms, values, beliefs, and practices that are particular to itself and that confer status upon those who exemplify them. What is praised in one group may be ignored or disdained in another. Whereas, for example, reading and classroom learning are valued in the middle class, "[a] lowerclass male who will not read books and makes little use of his high school classes will lose little or no respect among his peers, while the rarer one who reads difficult books and philosophy will be considered a bit odd. ${ }^{\text {"97 }}$ Furthermore, each stratum is aware that

Formal Organizations, 11 BeHAvioral. SCI. 357, 359 (1966) (stating that "people's social status in . . . society at large [is] determined by their status positions in various smaller groups").

${ }^{93}$ See id. at 367 (" $[\mathrm{P}]$ eople of high social status have relatively free social access to other individuals if they wish, which gives them a much freer choice among desirable potential personal associates (business contacts, personal friends, marriage partners) than people of lower social status can ever have."); see also Robert Hogan, $A$ Socioanalytic Theory of Personality, in NEBRASKA SYMPOSIUM ON MOTIVATION, 1982, at 55 (Monte M. Page ed., 1983).

9 See Harsanyi, supra note 92 , at 360 ("[A]n individual will be granted high status by the other members of the group ... as an incentive to perform activities personally important to these members . . . without regard to the usefulness, unimportance, or even harmfulness of his activities to society at large.").

${ }^{95} \mathrm{Id}$. at 359.

${ }^{96}$ See supra notes $40-41$ and accompanying text.

97 William J. Goode, The Celebration of Heroes: Prestige as a Social. 
its internal evaluations of beliefs and behavior are not necessarily shared by other groups; a group's status is determined by the general consensus shared by most groups about the overall pecking order-whether one is speaking of professions, organizations, classes, institutions, or departments.

A common denominator among all social groups is that they have barriers to entry. This is true even of low status groups that people of higher status typically do not wish to join. These barriers become apparent whenever people (for example, researchers, informants, and undercover agents) attempt to infiltrate a group and pass for one of its members..$^{98}$ Although suburban middle class youths, for example, typically have no desire to infiltrate urban youth gangs, gang members still have incentives to enforce standards and rules and demand conformity from those individuals who are attracted to their group and wish to gain its acceptance. Likewise, the grace of upper class members-their easy and relaxed manner, their disdain for those who try too hard-constitutes attitudes and poses that are learned and cultivated (arguably for the purpose of protecting their status and erecting barriers to class entry). Nelson Aldrich describes how people with "old money" try to give the impression that everything about them comes naturally, that they are born to good taste, style, manners, and grace-" "making the discriminatory judgments that mark the passage of a social connoisseur." They eschew overtly instrumental behavior and avoid talk of money, acquisition, and social climbing; their demeanor suggests that they have risen above materialism and acquisitiveness; they downplay their wealth and their social standing in a gracious self-effacing manner. But this effort to appear ever self-assured and self-possessed requires effort not unlike the effort of social strivers to present an inflated sense of self to others. The difference may well be that social strivers feel they need to advertise themselves more aggressively in order to gain an upper hand in their interactions, whereas members of the upper class can afford to express disdain for the rat race.

CONTROL SYSTEM 141 (1978).

${ }^{98}$ Thus, it is wrong to assume that barriers to entry in low status groups are unnecessary simply because no person wants to join these groups. Cf. ELSTER, supra note 5 , at 140 .

${ }^{99}$ NELSON W. Aldrich, JR., OLD MONEY: THE MYTHOLOGY OF AMERICA'S UPPER CLASS 82 (1988). 
Conformity in conventional parlance refers to the degree to which one identifies with groups that exist in the mainstream of society. In every society, there are prescribed cultural goals and approved cultural means through which to attain them. A person who subscribes to both the cultural goals and the institutionalized means of reaching them conforms to the cultural norms of the society. Nonconformists forsake this competition for prestige and status and adhere to the norms and values of alternative, less widely esteemed groups. ${ }^{100}$ But because both conformists and nonconformists alike abide by the normative constraints and incentive structures of their respective environments, one can usefully speak of general social conformity processes that operate within all social groups. In this regard, all political or ideological nonconformity is really another form of conformity, except that it is paid to groups that remain outside the mainstream of society. The real question, therefore, is determining which reference groups individuals choose to be guided by:

When nonconformity represents conformity to the values, standards, and practices of an earlier condition of society which are still enduring but not uniformly accepted, it is often described as "conservatism." Pejoratively, and sometimes exactly, it is described as "reactionary," particularly when it constitutes an effort to re-introduce values and practices which have been superseded or have simply fallen into neglect. When nonconformity represents conformity to values, standards, and practices which have not yet been institutionalized but are regarded as making up the normative system of future reference groups, it is often described as "radicalism."

Individuals tend to form their views on social issues within the context of specific group memberships. There may be overt social pressure to conform (threats of ostracism or retaliation, for example, against anyone who does not abide by the group edict), but subtle, unconscious influences on the individual to adopt the group's perspective on various matters are more common. When people conform to group norms, they rely on the guidance of those within their immediate social circle to develop a coherent understanding of events and situations. ${ }^{102}$ People tend to pattern their

${ }^{100}$ See Robert K. Merton, Social Theory and Social Structure 140-41 (enlarged ed. 1968).

101 Id. at 413-14.

${ }^{102}$ See Elihu Katz \& Paul F. Lazarsfeld, Personal. Influence: The Part 
attitudes and behavior after those who have social backgrounds similar to themselves because they are likely to share interests and perspectives.

Apparently no one is exempt from the elementary principle of political socialization that beliefs and values are likely to be related to social origins. In the Tibetan Buddhist religion, for example, when the Panchen Lama dies, he is reincarnated as an infant. ${ }^{103}$ The location and identity of the reincarnated Lama can be discovered through a series of divine signs. Using these leads, senior lamas locate a number of children who meet the criteria supplied by the oracles, and one of these children is eventually selected as the reincarnated Lama based on his ability to recognize a variety of objects that belonged to the deceased Lama. ${ }^{104}$ In theory, the new Lama could be located anywhere, but political and religious leaders remain acutely aware that the geographical location of the new Lama could hint at his future political inclinations. Therefore, when the Panchen Lama died in 1989, the whereabouts of the reincarnated Lama generated much political controversy because the Panchen Lama would have an influential voice on the question of Tibet's future relationship with China. ${ }^{105}$ If the Panchen Lama turned out to be a boy in China with parents who supported the Beijing government, he would probably favor maintaining existing ties to China. But if he were plucked from a family of anti-Communist Tibetan exiles in India, he would be inclined to support the movement for political independence when he grew up. ${ }^{106}$ Knowing what was at stake, religious and political authorities fought over where they should concentrate their search. ${ }^{107}$ All of which might lead one to ask, whatever happened to the idea of the One True Panchen Lama?

Played By People in the flow of Mass Communications 48-65 (1955); see also MUZAFER SHERIf \& CAROLYN W. SHERIF, REFERENCE Groups (1964).

${ }^{103}$ See Nicholas D. Kristof, Lamas Seek the Holy Child, But Politics Intrude, N.Y.

TIMES, Oct. 1, 1990, at A4.

${ }^{101}$ See id.

${ }^{105}$ See id.

106 See id.

${ }^{107}$ See id. ("China says that the reincarnation should be from Chinese territory, but ... we would like him to come from any place at all with the Dalai Lama confirming the selection." (quoting Nema Tsereng, a 22-year-old monk at the Jokhang Temple in Lhasa)). 


\section{B. The Columbia Theory of Social Influence}

An important contribution of the postwar Columbia school's research on opinion formation and political choice within communities was to show how a person's attitudes and actions are shaped and reinforced by his so-called reference groups. ${ }^{108}$ These groups include not only closely related individuals-such as family, friends, classmates, and co-workers-but also more abstract categories of individuals-such as professions or social classes to which people might aspire-who have a hand in molding attitudes and opinions. Social interaction, discussion, and the circulation of ideas within these groups leads to shared opinions on matters of common interest such as religion, culture, politics, and morality. Group members develop common evaluations and norms as the influence and conformity processes within ongoing social groups tend toward social equilibrium. ${ }^{109}$

Common opinions provide comfort and security to group members by giving "meanings for situations which do not explain themselves. ${ }^{\text {110 }}$

This is the way that stereotypes develop; and it is one of the reasons why ideas about what is real in religion or in politics vary from group to group. So many things in the world are inaccessible to direct empirical observation that individuals must continually rely on each other for making sense out of things. ${ }^{111}$

The classic laboratory experiment that mimics this process is Sherif's studies of the "autokinetic effect," an optical illusion in which a point of light shining in a darkened room appears to move, but actually does not. ${ }^{112}$ In one version of these experiments, several subjects are brought together and asked individually to judge how far the spot of light moves in a two-second interval when the light is turned on and off. They are then asked to repeat their judgments over a large number of trials. Subjects initially disagree about the degree of movement as each begins by offering his own private assessment. But over the course of the experiment they unconsciously pool their judgments and converge on highly similar estimates of the distance that the light travels. ${ }^{113}$ The subjects in

${ }^{108}$ See BERNARD R. BERELSON ET AL., VOTING 54-76 (1954) (discussing how socioeconomic and demographic factors affect political attitudes and voting behavior).

${ }^{109}$ See id.

${ }^{110}$ KATZ \& LAZARSFELD, supra note 102, at 53.

III Id. at 54-55.

112 See MuZafer Sherif, The PSYchology of Social NORMS (1936).

${ }^{113}$ See Muzafer Sherif, Group Influences upon the Formation of Norms and Attitudes, 
effect establish a group norm about how far the light moves, which is a compromise among the individual judgments. It is appropriate to characterize the point of convergence as a norm because the value established by the group continues to influence individual judgments, even when subjects are tested alone in follow-up experiments. ${ }^{114}$

What groups do, then, is develop common interpretations of social, and often physical, reality. One of the prime manifestations of this phenomenon in politics is the convergence of public opinion during election campaigns as people try to make sense of the issues and candidates. Between campaigns, voter preferences are more idiosyncratic and less anchored by social group memberships. Partisan turnover is much greater because there is less interest and political exchange outside of the election campaign. Individuals are consequently more strongly affected by factors such as the content of daily mass media stories that do not necessarily correlate with the influences of their social bases. ${ }^{115}$

\section{The Role of Interested Opinion Leaders During Elections}

All that is missing in the social-influence process just described is an engine to drive it. A model of social conformity needs a starting point because not everyone can be reacting to external influences simultaneously and one cannot assume that all individuals are passive. Some individuals must have sufficient motivation to assess the consequences of political alternatives and to make decisions based on these evaluations. ${ }^{116}$ These individuals provide the energy behind the diffusion process.

Not surprisingly, the more motivated individuals who provide the driving force behind social influence processes during elections are characterized by higher levels of interest in politics. Such individuals may make their decisions based on either personal benefits to be derived from election outcomes or, what is more likely to be the case, their perception of group benefits that will

in REAdings in Social PSycholocy 249, 250-56 (G.E. Swanson et al. eds., rev. ed. 1952).

${ }^{114}$ For a similar demonstration of group norm formation on social issues in a small housing community, see LeON FESTINGER ET al., SOCIAL PresSURES IN INFORMAL GROUPS: A STUDY OF HUMAN FACTORS IN HOUSING 73-100 (1950).

115 See BERELSON ET AL., supra note 108, at 138-47.

${ }^{116}$ See R. Duncan Luce, Analyzing the Social Process Underlying Group Voting Patterns, in AMERICAN VOTING BEHAVIOR 339 (Eugene Burdick \& Arthur J. Brodbeck eds., 1959). 
follow from the election. It is also fair to assume that they have personal incentives to remain informed about political affairs emanating from their roles and social positions. The Voting study conducted by Berelson, Lazarsfeld, and McPhee identified such individuals as opinion leaders. ${ }^{117}$ Such individuals gather information during the campaign in order to establish which candidate serves their interests.

A promising model of social influence therefore provides that class or group conformity is a product of group interests and that people develop awareness of such interests through a process of opinion leadership in which more motivated and independent individuals influence less interested voters. If group interests are preeminent, then social mobility out of the social class of the primary group will lead to the formation of new political preferences in accord with new interests. By introducing the concept of individual and group interests, the opinion formation process provides a starting point that a passive individual model lacks.

Even if individuals do not deliberately calculate that adopting certain norms and values will be instrumental to achieving their goals, they are likely to see that they have an interest in conforming to the norms of a group in which they seek acceptance. Conformity serves the purpose of signaling to others that one is willing to comply with group norms and goals. The specific opinions that one agrees with may not be as important as the display of conformity itself. Agreement per se conveys one's willingness to fit in and implies support for the status quo. Nonconformity of opinion, on the other hand, is an equally tell-tale sign that a person is a potential troublemaker whose behavior cannot be reliably predicted. ${ }^{118}$ Thus, a major reason why people attach significance to opinions is because they provide clues to the types of dispositions and intentions that a person has.

117 See BERELSON ET AL., supra note 108, at 109-14 (describing opinion leaders as "the active class, who occupy themselves primarily with public-affairs, who aspire to create and lead opinion").

${ }^{118}$ See Campbell, supra note 91, at 1107 (noting that group members place the greatest conformity pressure on the most deviant group members and tend to reject former group members who defect with more hostility than those who were never group members). 


\section{Individual and Collective Interest}

I should emphasize that group norms and opinions are by definition established and enforced by aggregates of individuals. Such norms, therefore, may serve general collective interests rather than the specific interests of individual members of the group. People will sometimes defend values that appear to run against their immediate self-interest in order to preserve social relationships that return long-term benefits. ${ }^{119}$

Consequently, the relationship between policy preferences and tangible economic or social interests may be apparent only when comparisons are drawn across social groups. For example, the working class as a whole is more likely to oppose busing than the middle class because its members feel that they are more likely to be affected by any scheme designed to reduce racial imbalance within school districts. ${ }^{120}$ Working class families are more likely to be affected by busing because they have fewer options and resources than middle class families. Higher income families have the ability to move to the suburbs or to enroll their children in a private institution, which allows them to avoid such schemes. Hence within the working class milieu, there will be strong pressures on individuals to conform to attitudes that are less racially tolerant and more opposed to busing policy. On the other hand, the middle class can afford to endorse racial norms that are more liberal and tolerant because its members on the whole are less susceptible to such policies. In this fashion, individually defined interests (that is, interests defined without considering one's ongoing relationships with others) may be compromised by powerful social influences that encourage conformity to group interests.

In a recent study, Green and Cowden substantiated the relationship between self-interest and actual participation in antibusing protests, as opposed to professed sympathies with antibusing forces. ${ }^{121}$ Efforts to deny any role for self-interest on this issue are curious because casual observation indicates that busing controversies have exploded in communities hit by court-ordered busing plans, but they rarely occur when the threat of busing is

${ }^{119}$ See Dennis Chong, Social Incentives and the Preservation of Reputation in PublicSpirited Collective Action, 13 INT'L POL. SCI. REV. 171 (1992).

120 See J. ANTHONY LuKAS, COMMON GROUND 27 (1985).

121 See Donald P. Green \& Jonathan A. Cowden, Who Protests: Self-Interest and White Opposition to Busing, 54 J. POL. 471, 475 (1992). 
remote. Therefore, at the community level of analysis, one finds good intuitive evidence that opposition to busing is related to the threat of busing.

Within these communities, however, there are likely to be social dynamics at work that attenuate the relationship between opposition and the degree to which one is directly affected by a busing plan. Expressing opposition to busing through public opinion surveys can reflect sincere dislike for busing schemes as a result of regular group dynamics and social influence processes. Green and Cowden suggest that people are less rational, or less focused on self-interest, when they form and express opinions than when they take political action. ${ }^{22}$ There is a more parsimonious way to describe what happens, however, than to treat individuals in dichotomous terms, operating according to one model in surveys and in line with another when they act. In surveys, people who oppose busing-an opposition that is a product of group conformity-say so; it is the side that they want to be seen to be on. Their friends oppose busing; the politicians they admire oppose busing. They get net benefits by indicating that they too are opposed. In other words, in adopting opinions that have no direct or immediate consequences, there will often be mitigating social forces that interfere with the operation of objective individual interests. Even those who were susceptible to the draft during the Vietnam War were not more likely to oppose the war, ${ }^{123}$ possibly because one's opinion of the war was greatly influenced by one's reference groups.

Political activity, however, is more costly than simply expressing one's opinion. Therefore, those who become involved in protests need additional incentives or benefits to offset the higher costs. Naturally, parents, those in predominantly white neighborhoods, and those without the resources to enroll their children in private schools are more likely to act because they stand to gain more by preventing busing from occurring in their district.

Social factors are also likely to undercut the relationship between narrow self-interest and protest activity. People who do not have children or who can transfer their children to private

${ }^{122}$ See id. at 475 (" $[\mathrm{P}]$ eople tend not to reflect on their personal interests when making political decisions in the context of a survey interview, but are stimulated to think about their interests when faced with the choice of whether to take action.").

123 See Richard R. Lau et al., Self-Interest and Civilians' Attitudes Toward the Vietnam War, 42 PUB. OPINION Q. 464, 474-75 (1978) (reporting that their findings were "contrary . . . to [their] hypothesis that self-interest would produce antiwar attitudes"). 
schools will sometimes be drafted nevertheless by their neighbors to engage in protest. Such individuals will go along for the same reason that they will be inclined to agree with the predominant community view on the issue. Their rational choice must give due weight to their ongoing social relationships within the community. ${ }^{124}$

\section{VAlues As Conventions}

The interest inherent in many political and social norms lies less in the actual substance of the norm than in the capacity of the norm to coordinate individual actions. There are many social choicessuch as the language we speak, the currency we use, the side of the road we drive on-where it does not matter (at least initially) which convention we follow, so long as we all follow the same one. ${ }^{125}$ In such cases, the norm chosen provides a basis for social coordination and collective action. Thus, people may derive part of the benefit of adhering to common beliefs from the instrumental advantages of those beliefs, but some utility may also stem strictly from the popular consensus surrounding them.

In History of Manners, Norbert Elias argued that increasing population density forced individuals to make adjustments in their personality and emotional structures. ${ }^{126}$ When populations were widely dispersed, individuals could act upon their aggressions and impulses more freely. When people began to live in close quarters and engage in regular interaction, however, manners were required to regulate and smooth over interpersonal relations. In Morals for Children, Erasmus promoted widespread adoption of social conventions to reduce the idiosyncrasy of symbols and actions and thereby facilitate communication. ${ }^{127} \mathrm{He}$ abhorred the use of exclusive conventions by any group, irrespective of class. "Previously, the practices of a particular group or milieu had been held up as norms. By contrast, Erasmus sought to use a common code of manners as

124 See, e.g., Dennis Chong, Collective Action and the Civil Rights MOVEMENT 125 (1991) ("Ongoing social interaction is more accurately modeled as an iterated prisoner's dilemma than as a single-play game."); RUSSELL HARDIN, COLLECTIVE ACTION 145-50 (1982) ("[I]t is generally agreed that players may rationally cooperate in iterated Prisoner's Dilemma.").

${ }^{125}$ See generally DAVID K. LEWIS, CONVENTION (1969); ROBERT SUCDEN, THE ECONOMICS OF RIGHTS, CO-OPERATION AND WELFARE (1986).

${ }^{126}$ See NORBERT EliAS, HISTORY OF MANNERS (Edmund Jephcott trans., 1978).

127 See 3 Roger Chartier, A History of Private life: Passions of the RENAISSANCE 172 (1989). 
a basis for establishing social transparency, which he considered a necessary precondition for broader social intercourse." 128 Civility was intended to foster social exchange.

\section{A. Transaction Costs and Externalities}

Common beliefs and attitudes can reduce the transaction costs of social exchange. The point of much conversation, gossip, and storytelling is to develop and share conventional reactions and emotional responses with kindred souls. ${ }^{129}$ Coordination around emotions, beliefs, and attitudes revealed in ordinary conversation and socializing provides the foundation for possibly more significant coordinated action in the future. As Allan Gibbard observed, the capacity to contemplate, speculate about, react to, and discuss the hypothetical greatly enhances one's opportunities to cooperate. ${ }^{130}$ It is a characteristic that enhances the biological fitness of the species.

Those who can work out together reactions to an absent situationwhat to do and what to feel-are ready for like situations. They are better prepared than they would otherwise be to do what is advantageous in a new situation, and they can rely on complex schemes of interpersonal coordination. On general evolutionary grounds, then, we might expect shared evaluation to figure centrally in a complex social life-and in human life it does. Much of our speech fosters shared reactions to absent circumstances. ${ }^{131}$

Coordinated emotions therefore help to establish conditions for reciprocity. One assumes that a person who does not feel the appropriate indebtedness for a favor will be less likely to reciprocate in kind.

Popular reactions to mass immigration highlight the problems of social uncoordination. Whereas a trickle of immigrants can be readily assimilated into the ways of the community, large waves of immigration often force the development of new social programs and institutions. In Wausau, Wisconsin, for example, an initially small influx of Southeast Asian immigrants in the 1970s was readily absorbed by the town. But subsequent waves of immigration, drawn to the budding Southeast Asian community, and high birth rates in

${ }^{128}$ Id. at 171 .

${ }^{129}$ See Allan GibBard, Wise Choices, APt Feelincs: A Theory of Normative JUDGMENT 72 (1990).

${ }^{150}$ See id.

${ }^{131} I d$. 
the immigrant population, have increased pressure on local resources. New schools have been built and additional teachers hired. Now that immigrant children comprise a quarter of the elementary school population, schools have had to offer special language training. Imbalances in the residential concentration of the immigrant population have also prompted school busing. Immigrants who could not find employment in the local economy have turned to public assistance. Immigrant youth gang activity has been reciprocated by native gang activity. What was once "novel and neat" has turned ugly and conflictual. ${ }^{132}$

At Cornell University, the comfort and appeal of one's own racial and ethnic group conventions has prompted several minority groups to establish separate dormitories on campus, which has intensified the pattern of voluntary housing segregation that already existed. ${ }^{133}$ Gay students who recently requested their own dorm were denied by university administrators intent on counteracting this trend. ${ }^{134}$ The sociological forces giving rise to these desires, however, are hard to resist. Minority students explain repeatedly that they feel more comfortable in familiar social surroundings. ${ }^{135}$ There are, so to speak, lower transaction costs, among those who share the same cultural background.

Minority students on North [campus] said it is less tense to live among your own. "By the end of the day at a school like this, you're tired," said Ruth Ramos, a Chickasaw Indian who lives in the Akwekon house. "This school is so English, so white, day in and day out you're a little more comfortable with your own. I'm the norm in this house."

132 See Roy Beck, The Ordeal of Immigration in Wasau, ATLANTIC MONTHLY, Apr. 1994, at 84, 84-86. There also appears to be a heavy psychic cost of feeling disoriented when one's conventions no longer prevail-as in Henry James's dismay upon returning to New England at the turn of the century to find that the crowds he encountered on the streets sounded entirely foreign to him:

$[N]$ o sound of English, in a single instance, escaped their lips; the greater number spoke a rude form of Italian, the others some outland dialect unknown to me .... No note of any shade of American speech struck my ear.... [T] he people before me were gross aliens to a man, and they were in serene and triumphant possession.

Henry James, The American SCene 231 (Horizon Press 1967) (1907).

133 See Michael Winerip, In School, N.Y. TimEs, Apr. 20, 1994, at B13.

${ }^{134}$ See id.

${ }^{135}$ See id. (noting that students voted by an $80 \%$ majority to reject an administrative proposal to adopt random housing assignments for freshmen in an effort to improve integration). 
"I know no one's going to be asking me why I wear my hair this way, ${ }^{n}$ says Ms. Myatt, the black freshman who lives in Ujamaa and wears her hair braided. "It gets tiring explaining yourself to white people all the time. Here I can come home and I know it will be music I like to listen to."

It's why Alison Nathan, of the Lesbian Gay and Bisexual Alliance, will continue pushing for a gay dorm. Ms. Nathan said that in a regular dorm, she can't be open about having a woman friend and feel comfortable. "Gays want a place where they can just be students without constantly justifying," she says, "so they can do their homework in peace, too."

Although many minority students consciously choose to live in separate houses, white students often gravitate to the predominantly white West Campus for reasons that are not explicitly racially based. ${ }^{137}$ Students on West Campus, they understand, are friendly and hold good parties. Or they learned from parents or friends of the family that West Campus is the most desirable place to live. Only as an afterthought do they realize that West Campus is almost entirely white-like the people who made the recommendation. Some white students expect West Campus to be predominantly white, but are shocked by the severe imbalance. ${ }^{138}$ In terms of Schelling's racial threshold model, they have a higher threshold for racial integration than is revealed by their choices, but individually they cannot do anything to alter the pattern of segregation. ${ }^{139}$ The best they can do is reinforce existing tendencies. Any individual might feel worse off in an environment where he was in the minority, and thus sticking with one's own group may not be optimal, but still better than the alternative. ${ }^{140}$ This coordination equilibrium therefore remains stable.

${ }^{136} \mathrm{Id}$.

137 See id.

${ }^{138}$ See id.

139 See ThOMAS C. SCHELling, MiCROMOTIVES AND MACROBEHAVIOR 137-66 (1978).

${ }^{140}$ See Winerip, supra note 133, at B13 ("'It's a sad commentary, the way we're all separated here,' said Gabe Jacobson, a Jewish sophomore who lives at . . . a mainly Jewish fraternity. 'But it's funny, because we like this, I think Cornell's a happier place." $)$. 


\section{B. Educating the Deaf}

To be sure, one's choice between conventions can also reflect strategic considerations, as in the current struggle over language that has split the community of people-both hearing and deafinvolved in the education of the deaf. The deaf community recently has begun to claim that it represents a linguistic subculture, and, like ethnic and racial groups, deaf people assert their pride and group identity. They express satisfaction with their condition and even a fervent hope that their children will be deaf like themselves. ${ }^{141}$ The vast majority of deaf children, however, have hearing parents; therefore, a critical communication barrier exists between deaf children and their parents, which inhibits intergenerational socialization and complicates education choice. ${ }^{142}$ The deaf sometimes react to hearing individuals with the same suspicion that one subculture displays toward another.

"If I happened to strike up a relationship with a hearing person," says $M J$ Bienvenu, a deaf activist speaking through an interpreter, "I'd have considerable trepidation about my [deaf] parents' reaction. They'd ask, 'What's the matter? Aren't your own people good enough for you?' and they'd warn, 'They'll take advantage of you. You don't know what they're going to do behind your back. ${ }^{m 143}$

Attempts to insulate a particular culture by outlawing or severely restricting the use of languages other than a favored one have the effect of keeping outsiders out as well as insiders in. Language requires a significant investment that must be made in the early stages of one's life and that will have a fateful impact on future opportunities. Nationalists in Quebec undoubtedly recognize that by requiring the children of immigrants to attend French language schools, they are trying to bind future generations to québécoise culture. Similarly, those who fervently advocate teaching deaf children American Sign Language (ASL) must recognize that these children will enjoy less access to the speaking world than those who master the ability to speak. To make ASL more attractive, activists have conducted a political and scientific campaign to discredit mainstreaming educational methods that aim to integrate the deaf $37-38$.

${ }^{141}$ Edward Dolnick, Deafness As Culture, ATLANTIC MONTHLY, Sept. 1993, at 37,

${ }^{142}$ See id. at 38 (noting that $90 \%$ of all deaf children are born to hearing parents).

143 Id. at 40 (alteration in original). 
into the general community. They also reject technological innovations, such as the use of cochlear implants to correct deafness because such methods imply that deafness is a disability rather than a separate linguistic culture. They compare these procedures to having an operation to alter one's race or ethnicity. ${ }^{144}$ ASL activists also argue that such methods are applicable only to a small proportion of deaf children and therefore hold out unrealistic hopes for most parents. ${ }^{145}$

The ASL offensive is entirely understandable as a strategy to create and sustain a cultural group. Language is a convention; its utility depends on how many other people speak and understand it and on how easy it is to translate the language for those who do not speak it. The popularity of ASL therefore depends on the degree to which ASL becomes the predominant form of communication chosen by the deaf. To the extent that efforts are made to integrate or "mainstream" deaf children, the strength of the deaf community is diffused.

[E]ven well-meaning attempts to integrate deaf people into hearing society may actually imprison them in a zone of silence. Jostled by a crowd but unable to communicate, they are effectively alone. The problem is especially acute in schools, where mainstreaming has led to the decline of residential schools for the disabled and the deaf and the integration of many such students into ordinary public schools. Since deafness is rare, affecting one child in a thousand, deaf students are thinly scattered. As a result, half of all deaf children in public school have either no deaf classmates at all or very few. ${ }^{146}$

The deaf culture movement's attempt to encircle the deaf community and create a society that shares a common language may be seen as a rational response to the limited mainstream alternatives a deaf person faces. Because integration is difficult to achieve and undermines the deaf community by dispersing its collective resources, building a deaf culture that consciously rejects efforts to conform to the mainstream and takes pride in the characteristic that the mainstream treats as a physical handicap becomes an attractive strategy. Deaf culture ideology therefore promotes actions that

144 See id. at 43 ("[Because] deafness is not a deprivation, the argument runs, talk of cures and break-throughs and technological wizardry is both inappropriate and offensive-as if doctors and newspapers joyously announced advances in genetic engineering that might someday make it possible to turn black skin white.").

115 See id.

${ }^{146}$ Id. at $43,46$. 
assist group survival at the same time that it encourages the deaf to accept their condition with pride.

\section{INTERESTS CReAted By PRIOR INVESTMENTS IN VALUeS}

Finally, even those social values and norms that have not been formed explicitly from interests-the conventions, ideologies, and beliefs acquired from reference groups without much reflection-are likely to become imbued with interests once they become widely adopted. People tend to develop a vested interest in their social norms and values because they have formed plans and acted on the basis of those norms and values.

A system of norms and values affects the status and opportunities of different groups in society. Values, norms, and traditions therefore serve people's interests sometimes merely by virtue of the fact that people have built their lives around them. Early lifestyle choices constrain future choices that individuals are able to make. Once people have made a commitment to a particular way of life, it is difficult for them to adjust to another set of practices because such commitments constitute investments that may be irreversible. In this fashion, values, norms, and traditions come to be defended as interests.

Every individual invests in developing a particular repertoire of skills, only some of which have universal appeal and status. Different social groups will value different beliefs and evaluations, and consequently a person may not be able to reinvest completely his skills in a new market. ${ }^{147}$ "A different social circle may, for example, be made up of people from varied ethnic or class backgrounds, tastes, and patterns of recreation, and one's formerly applauded social routines may be received by them in awkward silence." 148 This is why most social change will encounter resistance and will often occur mainly as a result of generational replacement rather than conversion.

The relative status of a group within a social system will affect its attractiveness to actual and prospective members. In this sense, every group operates its own internal prestige market, but each group is also part of a larger market. Although individuals

${ }^{147}$ See Anderson, supra note 23, at 92 (noting that street-oriented youths make the code of the street a part of their identity and thus have difficulty adapting to situations that require polite and deferential behavior).

${ }^{148}$ GOODE, supra note 97 , at 114 . 
constantly move among different groups and subsystems within society (which is the essence of social mobility), individuals also have strong incentives to remain within a particular subsystem and to insulate that system from external penetration. "One of the noneconomic benefits of remaining within one's neighborhood ethnic group or organization is precisely the avoidance of a free social market, that is, the avoidance of unremitting and full-scale competition in courtship and marriage, friendship groups, social clubs, and general esteem."149 Because prestige varies across social groups, individuals will be motivated to join higher status groups, but this option will be closed to many who do not have the ability to make such a transition.

\section{A. Deciding Between English and ASL}

The side that parents of deaf children take in the debate over whether their children should be taught English or ASL will be binding. Even if the parents choose English, there is a very high chance that their child will fail to master English speech, and it is certain that his lip-reading ability will be highly imperfect. ${ }^{150}$ His reading skills will also tend to lag behind hearing children of the same age. ${ }^{151}$ It is, unfortunately, impossible to predict how well any particular deaf child will fare if his parents decide that he should learn English.

ASL, on the other hand, gives its speakers the capacity to express any thoughts and ideas that can be expressed in English or any other language, and it is straightforward to learn. ${ }^{152}$ However, hearing parents have difficulty learning ASL (it is like acquiring a foreign language) and therefore will have difficulty communicating with their children. Moreover, deaf people who do not know English will be boxed out of mainstream society. Finally, ASL is a spoken language without a written counterpart and is not conducive to developing reading skills. Consequently, children who learn ASL

149 Id. at 112.

${ }^{150}$ See Dolnick, supra note 141 , at 39,48 (noting that when lip-reading, the average deaf person recognizes "perhaps three or four words in every ten" and that " $[t]$ he vast majority of deaf children will never develop intelligible speech").

${ }^{15 l}$ See id. at 40 ("The average deaf sixteen-year-old reads at the level of a hearing eight-year-old. When deaf students eventually leave school, three in four are unable to read a newspaper.").

${ }^{152}$ See id. ("[ASL is] a language equally suitable for making love or speeches, for flirtation or mathematics." (quoting Dr. Oliver Sacks)). 
exclusively are not likely to have the skills needed to compete in society. ${ }^{153}$

Educational and linguistic choice raises a coordination problem, or in this case a multitude of coordination problems because consideration has to be given both to coordination among the deaf as well as to coordination between deaf and hearing people. Whatever choice is made between ASL and English, one should expect the chooser to have a strong interest in seeing others make the same choice. It should come as no surprise that the main solution that has been implemented in schools for the deaf is "total communication"-in effect a compromise of approaches-in which teachers use signing and speaking and writing English in conjunction with each other. ${ }^{134}$

The investments people make (or elect not to make) in education and training and in their social relationships are guided by a given system of values and norms. Consequently, there will be individuals and groups who have a stake in protecting the culture they have been raised in because they will suffer a loss of prestige, status, and economic opportunity if new values are introduced.

\section{B. Women Abortion Activists}

New values typically call for new skills that will place members of society brought up in the old regime at a competitive disadvantage. Therefore, some individuals will defend existing beliefs and values until the pressure for change grows too strong to resist. The current abortion debate, for example, revolves around the particular role for women-as mothers, housewives, homemakers, or as professional breadwinners-that will be accorded greater prestige in society. At stake in this conflict is a conception of women and of motherhood that will tend to benefit either wage earning or nonwage earning women. These two classes of women have on average vastly different resources at their disposal; therefore, they are differentially equipped or prepared to adjust to the outcome of this policy debate. "While on the surface it is the embryo's fate that seems to be at stake, the abortion debate is actually about the meaning of women's lives." 155

153 See id. at 51 (noting that "deaf culture has a marked anti-book bias," and that consequently deaf children are "in danger of being exploited, because low-end jobs are all that will be available to [them]").

154 See id. at 50.

${ }^{155}$ KRISTIN LUKER, ABORTION AND THE POLITICS OF MOTHERHOOd 194 (1984). 
That contrasting interests are involved in the formation of abortion attitudes is reflected in the demographic and socioeconomic variation between pro-choice and pro-life activists. Prochoice activists are much better educated on average, have higher incomes, are more likely to be drawn from the professions and, if married, to be married to professional men. ${ }^{156}$ Pro-life activists are more likely to be married, have more children on average, and are more likely to attend church and to say that religion plays an important part in their lives. ${ }^{157}$

These demographic profiles indicate that, at least within the activist ranks, pro-life and pro-choice women have invested differentially in preparation for the social roles they have chosen. Abortion rights or the denial of such rights serves the values and lifestyles that women have invested in. Pro-life women are typically ill-prepared to pursue a professional life because they have not obtained sufficient education and are constrained by their marital and childcare responsibilities. Consequently, any degradation of the role of housewife and mother will come at their expense. Prochoice women, on the other hand, have an obvious stake in preserving the right to an abortion because such a right increases their opportunities as career-oriented women. ${ }^{158}$

Although pro-life and pro-choice activists possess different social characteristics, abortion attitudes do not stem entirely from one's current life situation. Abortion attitudes are also shaped by general attitudes toward family, career, marriage, and children that are produced by early socialization. Nevertheless, early socialization and contemporary circumstances and pressures usually exert a consistent chain of influences. "The values that lead pro-life and pro-choice women into different attitudes toward abortion are the same values that led them at an earlier time to adopt different lifestyles that supported a given view of abortion." 139 Pro-choice and pro-life women typically have contrasting social origins; they grow up in environments that place sharply varying values on the roles of conventional and career women. But by investing in the roles that were upheld as ideals in their communities during the

${ }^{156}$ See id. at 194-97.

157 See id.

${ }^{158}$ Likewise, career women participated in pro-ERA groups at higher rates than traditional women did. See Kent L. Tedin et al., Social Background and Political Differences Between Pro- and Anti-ERA Activists, 5 AM. POL. Q. 395, $400-05$ (1977).

${ }^{159}$ See LUKER, supra note 155, at 199. 
course of their socialization and upbringing, they have to some extent constrained their options in the future: "activists on both sides of the issue are women who have a given set of values about what are the most satisfying and appropriate roles for women, and they have made life commitments that now limit their ability to change their minds. ${ }^{n 160}$

Pro-life and pro-choice women will therefore be differentially affected by how women's roles are defined and by which roles will be granted the most prestige by society at large. If a woman's reproductive role is given primacy, then women who wish to compete with men in the marketplace for jobs will be harmed by the assumption among employers that they are not as devoted to their careers as men. ${ }^{161}$ On the other hand, if a woman's professional role is accorded greater respect, this status undermines how traditional women are likely to be treated in comparison to those women who have invested a greater part of their lives in education and training. In this regard both sides in the abortion conflict adopt positions that reflect their respective preparation for a meaningful role in society.

From a rational choice perspective, people eventually change their values when it is no longer beneficial to continue conforming to them because of changes in social conditions. Contrary to the assumptions of the symbolic theorists, systematic resistance to changes in social values can constitute evidence that supports, rather than contradicts, the rational choice model. The main opponents to changes in social values will be those groups with a vested interest in the traditional ways of doing things.

\section{Cultural TheOries CREATE INTERests}

The discussion to this point has traced the role that interests play in the formation, transmission, and defense of group norms. Now I wish to come full circle and revisit the claim I offered at the beginning of this Article that rational processes cannot carry the full weight of explaining the origin of group norms and values and the animus behind normative conflicts. In addition to rational choice, psychological biases in gathering and interpreting information play

${ }^{160} I d$.

${ }^{161}$ See id. at 201 (noting that "employers might choose to discriminate against women because they might require maternity leave and thus be unavailable at critical times ${ }^{n}$. 
an essential role in explaining how many conventional features of culture-beliefs, values, and norms that groups have developed a consensus around-eventually become defended as being vital to group health and prosperity. In this manner, culture becomes connected causally to political and economic goals.

Interests, therefore, stem not only from direct utilitarian reasons-such as the advantages of coordinating around conventions and protecting prior investments in institutions-but also from reinforcing social theories about the cultural foundations of social and economic progress. Once cultural beliefs become embedded in theories of economic growth and progress, threats to those beliefs are perceived to have significant material consequences. Cultural norms and practices thus become tied via this social psychological route to personal and group interests. Such extrapolations, however, usually rest on unreliable methods of information gathering, which give rise to biased inferences and rationalizations. ${ }^{162}$

Racial and ethnic stereotypes are a prime example of group beliefs that can originate in this fashion. In general, new groups enjoy fewer opportunities in the societies they enter because they are likely to be handicapped by language deficiencies, weak social ties, and a lack of familiarity with existing conventions. Their lower levels of economic success and the manifest differences between them and the majority tend to fuel prejudice against them. People go from observing that different racial and ethnic groups consistently enjoy varying levels of socio-economic success to believing that differential success is explained by inherent group characteristics. Groups at the bottom of the socio-economic ladder are thus presumed to suffer from a lack of ability, intelligence, character, desire, and ambition, whereas groups that are more successful are thought to be blessed with favorable traits and dispositions. ${ }^{163}$

The path to respectability and trustworthiness in our society requires one to live up to an entire constellation of norms and conform to a variety of characteristics and traits. For example, in the nineteenth century, nativists continued to treat immigrant

162 For overviews on biases in belief formation and information processing, see JoNATHAN BARON, THINkING AND DECIDING (1994); RichaRD NISBETT \& LEE ROSS, HuMAN INFERENCE: STRATEgIES AND SHORTCOMINGS OF SOCIAL JUdGMENT (1980).

163 See MichaEl A. Hogc \& Dominic AbRams, Soclal IDENTIFICATIONS 64-91 (1988) (analyzing the mental processes leading from stereotyping to ideological beliefs). 
groups who lived up to most of the tenets of Victorian culture as aliens because they remained different in crucial regards. ${ }^{164}$ Trusting other people requires sharing important similarities with them concerning their overall emotional, psychological, social, and physical makeup. One distrusts those who think or act in unusual ways because one can no longer assume that they will react to situations in the same way as one does. ${ }^{165}$ At the turn of the century, for example, Protestants despised Irish Catholics because they dressed and spoke differently and held different religious ideas. Catholics were unpredictable. They violated the acknowledged rules of fighting-kicking below the belt, beating up small boys, and loading their snowballs with rocks. They also drank to the point where they lost control. ${ }^{166}$ Each such act violated the majority's understanding of what constituted normal behavior. ${ }^{167}$

Those who do not conform to conventional ways are stigmatized and met with suspicion. The stigma detracts from other attributes that might be creditable ${ }^{168}$ and becomes embedded in an elaborate theory about why people with the stigma should be discredited:

By definition, of course, we believe the person with a stigma is not quite human. On this assumption we exercise varieties of discrimination, through which we effectively, if often unthinkingly, reduce his life chances. We construct a stigma-theory, an ideology to explain his inferiority and account for the danger he represents, sometimes rationalizing an animosity based on other differences, such as those of social class. ... We tend to impute a wide range of imperfections on the basis of the original one. ${ }^{169}$

Those who are stigmatized are disqualified from certain life activities. Some individuals may reject the standards of evaluation that discredit them, but usually stigmatized people employ the same norms and therefore share in the belief that there is something discreditable about themselves. Eventually, self-loathing may lead to efforts to disguise or remove the stigma. ${ }^{170}$

In the mid-nineteenth century, for example, drinking was a stigmatized trait that was believed to reflect unreliable character.

\footnotetext{
164 See Stanley Coben, Rebellion Against Victorianism 4 (1991).

${ }^{165}$ See supra notes $129-31$ and accompanying text.

166 See COBEN, supra note 164, at 29-30.

${ }^{167}$ See id. at 30.

${ }^{168}$ See ERving Goffman, Stigma 5 (1963).

${ }^{169}$ Id.

${ }^{170}$ For a discussion of how discredited and discreditable individuals manage information about themselves, see $i d$. at 41-104.
} 
Alcohol consumption reflected impulsiveness, recklessness, and unreliability-characteristics associated with failure and ruin. ${ }^{171}$ Sobriety, in contrast, reflected self-control, diligence, and seriousness; it was a behavior associated with respectable middle class standing. A person who sought upward mobility had to abide by this standard. "Prohibition was not seen as an isolated issue but as one which pitted cultures against each other." 172 "[Abstinence] was one of the ways society could distinguish the industrious from the ne'er-do-well; the steady worker from the unreliable drifter; the good credit risk from the bad gamble; the native American from the immigrant. ${ }^{\text {"173 }}$

Popular theorizing leads people to believe that the socioeconomic status quo reflects the natural order of things. Henry Seidel Canby recalled that when he was growing up, he thought of all Greeks as fruit stand operators and all Italians as rail yard workers. He did not remember there being much in the way of social mobility among those groups. ${ }^{174}$ People have a general inclination to attribute causal importance to salient differences between groups, beginning most obviously with racial or ethnic features, but extending also to manners and customs.

The members of outgroups are seen to be less fit for leadership and responsibility; they are distrusted because they do not conform to the conventions of society. But self-interest does not adequately explain the dynamics of group relations in these cases. If dominant groups simply wanted to reduce competition, they would not make parallel efforts to acculturate those who were different. Those in power typically create barriers between themselves and new groups but, at the same time, work to convert the new groups to traditional ways. ${ }^{175}$

In this environment, it can be rational for minority groups to adapt by creating and supporting their own institutions. Ethnic identification in the United States remains strong despite the increased participation of ethnic groups in the mainstream institutions of American society. Ethnic enclaves and neighbor-

171 See GUSFIELD, supra note 3, at 146.

172 Id. at 124 .

${ }^{173}$ Id. at 5-6.

174 See COBEN, supra note 164 , at 30.

175 Cf. Lawrence W. LeVine, Highbrow/Lowbrow: THE EMERGENCE OF Cultural Hierarchy IN AMERICA 171-242 (1988); id. at 184 ("[T]he arbiters of culture turned their attention to establishing appropriate means of receiving culture."). 
hoods persist, as do ethnic community groups and organizations. In addition, race and ethnicity remain salient features of public life, affecting marital patterns, residential choice, friendships, as well as employment opportunities. Despite enjoying greater social mobility, minorities who might wish to downplay their ethnic origins are seldom able to do so simply because people continue to use ethnicity as an important marker in their social and professional relationships. ${ }^{176}$

Ironically, group interest in forming separate institutions in response to prejudice, combined with cultural conservatism, will sometimes lead groups to defend cultural values that have begun to limit the opportunities and well-being of their adherents, even if they initially seemed adaptive. For example, in the late nineteenth century the social order of the company town of Steelton, Pennsylvania, was based on race and ethnicity. Native whites (Anglo-Saxon Protestants) and Irish and German immigrants dominated the community; from their circles came the politicians, the businessmen and merchants, and the foremen in the local steel mill. ${ }^{177}$ Menial and unskilled work was reserved for Eastern and Southern European immigrants who had recently arrived in the country and blacks who had migrated to Steelton from the South in pursuit of higher industrial wages. ${ }^{178}$ Economic discrimination was reinforced by residential segregation. Neighborhoods were segregated along the same racial and ethnic lines as work groups in the mill. ${ }^{179}$

Steelton's immigrants coped by building separate communities and supporting their own religious and cultural institutions, which provided them with community life, status, and respect. ${ }^{180}$ The growth of these separate cultural institutions, however, magnified the differences between the practices and conventions of different ethnic groups. With so little opportunity for social exchange between groups, prejudices and stereotyping flourished. Limited social mobility among immigrant families created disdain for formal education; reliance on kinship and ethnic ties for employment

${ }^{176}$ See Michael Parenti, Ethnic Politics and the Persistence of Ethnic Identification, 61 AM. POL. SCI. REV. 717, 717-26 (1967); see also RICHARD D. ALBA, ETHNIC IDENTITY (1990).

177 See JOHN BODNAR, STEELTON at xv (1977).

${ }^{178}$ See id.

179 See id. at xvi.

${ }^{180}$ See id. at xviii ("Steelton's immigrants turned inward and formed ethnic communities as did most other newcomers to urban American in the early decades of this century."). 
perpetuated working class status across generations. ${ }^{181}$ Pride in ethnic history and antagonism toward outsiders reduced the likelihood of intermarriage with members of other groups. ${ }^{182}$ Thus, segregation and discrimination forced the first generation of immigrants to develop a separate culture, which fostered distinct group values and practices. The development of this group culture had the unintended effect of reinforcing segregation and limiting the opportunities and aspirations of subsequent generations, which in turn perpetuated their isolation and dependence on ethnic ties. ${ }^{183}$ In this manner, cultural practices that were once adaptive had become destructive.

People rationalize cultural differences by incorporating them into a typically self-serving (but, as the Steelton example illustrates, sometimes unintentionally self-defeating) theory that explains social stratification. More often than not, the dominant cultural groups revel in their own superiority and believe that their culture serves both themselves and the larger public good. Therefore, they assume that it is essential to keep rival ideas and practices out because such ideas threaten the status quo.

Do people hold such social theories because they maintain the status quo and undermine disadvantaged groups? It may be the case that antipathy-driven by largely psychological motives, such as fear of the unknown or unusual-comes first, followed by prejudice, which subsequently drives actions that restrict the opportunities of the outgroup. People do not form fearful beliefs in order to keep groups down; rather, certain groups are kept down because people truly are afraid of unaccustomed manners and appearances and act on such beliefs. When new groups push for greater political and economic equality, beneficiaries of the old order may recognize that forms of prejudice and discrimination embodied in existing social institutions and popular attitudes help sustain their social and economic position-and therefore may fight to preserve the status quo. These forms of prejudice may have originated largely from psychological motives, however, and the dominant group's interests may have been served mainly as a by-product. Here is an instance, then, where beliefs and preferences-prejudices and stereotypes in this case-based on limited information and faulty inferences can be subsequently hard to change because they are reinforced by a status

\footnotetext{
${ }^{181}$ See $i d$. at $129-30,135-36$.

182 See id. at 127.

${ }^{183}$ See id. at 144.
} 
quo that works to the benefit of some groups at the expense of others.

\section{Culture AND Economics}

A combination of psychological and rational motivation thus appears to be central to normative conflict. Even though the Temperance movement is the classic case study of a status issue, the politics of that era offers a vivid example of how ideas about culture become entangled with political and economic goals. As new ethnic groups in the United States began to acquire more political power in the cities, nativist groups felt their control over culture and politics wane. ${ }^{184}$ Traditional practices and ways of life were transformed by new technologies, ascendant groups, and broadscaled social changes. In the 1920s, the old guard of white, AngloSaxon, Protestant families fought against encroaching social change on a number of fronts and were sometimes successful in delaying reform:

[S]mall-town and rural Protestants were waging a vigorous defense of their cultural values against their rapidly gaining foes-the advancing Catholics and minority ethnic groups on one side and the modernists in religion and secularists in intellectual culture on the other. The Ku Klux Klan, Prohibitionism, the campaign against evolution in the schools, anti-Catholicism and the whispering campaign against $\mathrm{Al}$ Smith were all aspects of this struggle. ${ }^{185}$

The Temperance movement should be viewed in the context of this broader reaction against new political and economic forces in American society. Nativist groups supported Prohibition in an attempt to maintain control over a distinguishing feature of the traditional culture. But Temperance was only one highly symbolic element in this conflict. Prohibitionists pointed to alcohol consumption as a reliable indicator of individual and social decline, but this attack also reflected the larger skirmish over whether rural or urban interests would control the political and economic future of America. The issue was not only whether alcohol consumption would be permitted, but whose way of life would prevail: which curriculum would be taught to schoolchildren; what standards of sexuality and morality would be reinforced; how much immigration

184 See HOFSTADTER, supra note 4 , at 78.

${ }^{185} \mathrm{Id}$. 
would be permitted; what regions of the country would be most influential; which groups would dominate the Democratic party.

Threats posed by new groups usually exceed simple loss of honor or status for traditional members of the community. New groups also have the potential to impose their beliefs on others through political action. Moreover, members of the established community usually believe that these foreign beliefs will be detrimental to the community. In a new epilogue written more than twenty years after the original publication of his book, Symbolic Crusade, Gusfield amends the details of his account of the Temperance and Prohibition movement by giving greater weight to people's concerns that drinking caused a variety of social ills including crime, immoral behavior, and the decline of religious belief. ${ }^{186}$ As the composition of society rapidly changed at the turn of the century, people experienced growing disorganization and disorder, which led them to take actions to regain control. The actions they took, however, were not merely designed to preserve their higher status in society; rather they reflected a direct attempt to address the causes of real social problems. When community institutions such as the church proved incapable of solving the problems associated with alcohol consumption, people demanded government intervention. Such actions were based on existing social theories about the causes of social stability and progress and the sources of social decay and were not merely frustrated reactions to ill-defined anxieties and stresses. ${ }^{187}$

As this account makes clear, it is difficult to distinguish between status and interest in the rural Protestant agenda. Issues that are ostensibly about status and cultural mores are also interrelated with matters of economic and political power. When new groups gain prominence in society, they bring with them their habits, religion, morality, and style of life, and, by virtue of their economic and political standing, these cultural elements take on increased status in society. ${ }^{188}$ Gusfield draws too sharp a line between cultural and

${ }^{186}$ See GuSFIELD, supra note 3, at 195-96 (2d ed. 1986).

187 When national prohibition took effect in 1920, liquor bans already existed in two-thirds of the states, but teetotalers believed that national enforcement was needed to bring the problem under control. Ultimately, the 18th Amendment was repealed in response to straightforward economic arguments that the liquor industry would generate needed jobs during the Depression. See Kermit L. HaLL, The MAGIC MIRROR 251 (1989).

${ }^{188}$ See Dennis Chong \& Anna Marshall, When Morality and Economics Collide (or Not) in a Texas Community (1995) (unpublished manuscript, on file with author) 
economic politics when he writes that " $[t]$ he neo-Populism of Prohibition was a political philosophy devoid of economic content but filled with the cultural tones of an attacked status group. ${ }^{\text {189 }}$ Cultural conflict was a contest over who would establish not only the cultural norms, but the political and economic norms of the nation. One anti-Saloon League spokesman drew the sides neatly when he commented, "When the great cities of America actually come to dominate the states and dictate the policies of the nation, the process of decay in our boasted American civilization will have begun." ${ }^{190}$ As this quote implies, politics, economics, and culture are fully intertwined; cultural values and ways of life are seen to be integral to sustaining the political and economic structure of a nation. Thus, a contest over a style of life is simultaneously a contest over what aptitudes, personal traits, education, social background, and vocational training will be accorded the highest value and status in society.

Established groups seeking to retain their position in the political and social status hierarchy therefore do not discriminate between features of their competitors. They do not, for instance, grant legitimacy to the morals and values of new groups and, at the same time, take the position that these groups should not receive equal standing in the political process. Rather, the opposition to the upstart group is broad-brushed and all-encompassing because cultural, political, and economic institutions tend to be regarded as an integrated system. To the rulers go the spoils of establishing what cultural norms and political values will dominate the day-to-day affairs of the society.

As social norms change, they affect the standing of attitudes and behavior, which in turn can affect the likelihood that groups will engage in political mobilization. After the repeal of the Eighteenth Amendment, the respectability of the Temperance movement gradually declined even within areas of the country where Temperance formerly enjoyed considerable popularity. ${ }^{191}$ There was, in particular, a marked decline in the proportion of individuals from the upper and middle class who were active in the Women's

(presented to the Annual Meeting of the American Political Science Association, Chicago 1995).

${ }^{189}$ GuSFIELD, supra note 3, at 126.

${ }^{190} \mathrm{Id}$.

${ }^{191}$ See id. at 129. 
Christian Temperance Union. ${ }^{102}$ Supporters of Temperance became acutely aware that they were a dwindling minority in the country and becoming increasingly isolated from mainstream opinion. "The public thinks of us-let's face it-as a bunch of old women .... I've been viewed as queer, as an old fogey, for belonging to the WCTU. ... . This attitude was not true thirty years ago." 193 As this perception of Temperance supporters became widespread, it became increasingly difficult for the WCTU to recruit new members, especially from the professions. ${ }^{194}$

These dynamics highlight what happens when an idea loses its imprimatur. Whereas abstinence once connoted respectability and traditional mores, the defeat of Temperance altered popular perceptions of teetotalers and changed the incentive for individuals to be identified with the movement. By the twentieth century, even the church had moderated its position on drinking.

Where once the abstainer could identify himself with the publicly dominant norms of his own community and reference group, today he is more likely to find that Temperance ideals are deviant even within the Protestant middle-class society to which he has felt affiliated. Temperance norms are increasingly illegitimate or invalid. ${ }^{195}$

Drinking practices therefore served as an indirectly biased traita trait that was valued because successful people possessed it, even though that trait was not directly responsible for their success. ${ }^{196}$ Successful people in the traditional Protestant culture did not drink; therefore, drinking indicated that one did not belong to the dominant culture. As this culture gave way to a new economic order, however, individuals spearheading this economy manifested different traits; members of the new middle class drank alcohol, which gave alcohol respectability within the modernist culture. Alcohol became a new sign in this culture, an indication of tolerance and sociability: "There is a realization of the increased dominance of new middle-class norms in which the abstainer appears as an object of ridicule, contempt, and inferior status. $\$ 197$

192 See id.

193 Id.

19 See id. at 131.

${ }^{195} \mathrm{Id}$.

196 See Robert Boyd \& PETER J. Richerson, Culture ANd the Evolutionary Process 243 (1985).

197 GuSFIELD, supra note 3, at 133. 
With the demise of the Temperance movement came a change in the meaning of drinking. Drinking now reflects the ability to lower one's guard and to relax and enjoy oneself. Indeed, it can even be used to signify one's sociability-the ability to subordinate oneself to the norms and activities of the group. Thus, the practice of drinking has taken on new, positive connotations in line with social and economic change. As Burke once noted, custom reconciles us to everything.

\section{CONCLUSION}

Competing theoretical models make their contribution by highlighting certain explanatory mechanisms at the expense of others, usually overstating the case for their importance. Sociological and economic theories of social action are no exception. They emphasize values and group identifications, and opportunity costs, respectively, as the prime motivators of individual action.

The economic model, however, underestimates the extent to which motivation from enduring group loyalties and values can override changes in the opportunity costs of available choices. People sometimes resist cultural change even when environmental changes undermine the original rationale for their values and actions. Also, much value formation and transmission occurs through imitation and conformity without involving explicit instrumental calculation. These processes are guided more indirectly by self-interested considerations, such as through opinion leadership by informed elites who provide signals to group members about where their interests lie.

At the same time, by emphasizing cultural inertia and the force of abstract values, the sociological model understates the influence of interests in explaining value formation and change and social conflict over ways of life. With its emphasis on socialization, symbolic values, and group attachments, the sociological approach offers only a partial story about why people make strong emotional investments in their opinions and why powerful collective pressures toward conformity exist in society. Once again, sociological and social psychological models pay more attention to the individual characteristics that are reliable antecedents of social conformity than to the instrumental reasons that may explain why groups of individuals might coordinate themselves around certain norms.

Values such as political ideology reflect long-term commitments as well as beliefs about social causality. As such, these values can be 
readily incorporated into a rational decision making model. Likewise, value formation and change are influenced by interests. First, individuals join groups in order to achieve goals that can be reached only through collective efforts; conformity to group norms is required for membership and is given in exchange for a share of group benefits. Second, compliance with social conventions smooths social exchange and reduces transaction costs. Some conventions are supported because they are believed to be more efficacious in pursuing group interests. Third, some values and norms originate from direct consideration of self or group interest and are favored because they facilitate those interests. Fourth, even when many actors conform to community pressure without conscious calculation of personal interests, there are usually some interested actors in the picture who promote one basis of coordination rather than another. Finally, long term investment in group norms can create a vested interest in defending those norms when group members do not possess, or do not wish to expend, the resources necessary to adapt to new norms.

Society is organized not only along class lines, but in terms of religion, race, ethnicity, gender, ideology, and other salient social categories. Therefore, interests will be shaped significantly by group affiliations that are based on ascriptive characteristics as well as on socio-economic factors. One pursues some interests on an individualistic basis, but many interests are pursued in collectivities and are defined in group terms. ${ }^{198}$ Groups organize around their beliefs about the world, and they develop institutions and patterns of behavior on this basis. These patterns tend to serve their interests at the expense of outside groups. Conflict over social issues may conveniently be defined as status politics because they involve differences of lifestyle and morality, but how such issues are resolved usually has material implications for the interested parties.

Still, not every aspect of social conflict is readily explained by rational processes. Economic models have difficulty accounting for social psychological biases in the way that people draw causal inferences relating their traditions and norms to economic and political goals. The cultural theories that people develop relating politics and economics to their morality and way of life provide the rationale for their defense of the status quo and may be an essential source of the peculiar animus that often accompanies social conflict

${ }^{198}$ See generally WiLl Kymlicka, Multicultural. CitizenshiP (1995). 
over norms. Although these cultural theories typically rationalize vested interests, they can also constrain individual choices and thus become unintentionally self-defeating.

Values shape both preferences and evaluations about alternatives; shared preferences support social conventions and permit coalitions and groups to form. Coalitions, in turn, provide the foundation of political power. Once coalitions are in place, people who benefit from the status quo will want to maintain them. Therefore, they will fight to maintain the values and practices that made the coalitions possible in the first place. When social norms and values change, new coalitions become feasible. The constitution of culture affects what kinds of partnerships are more likely to form than others. It will therefore be in the interest of groups to defend their values because institutions, conventions, and practices are built around them and because group members have irrevocably invested in those values, even if the values did not originally emerge purely from self-interest. 